\title{
When Is the Optimal Lending Contract in Microfinance State Non-Contingent?*
}

\author{
Doh-Shin Jeon $^{\dagger}$ and Domenico Menicucci ${ }^{\ddagger}$
}

March 9, 2010

\begin{abstract}
Whether a microfinance institution should use a state-contingent repayment or not is very important since a state-contingent loan can provide insurance for borrowers. However, the classic Grameen bank used state non-contingent repayment, which is puzzling since it forces poor borrowers to make their payments even under hard circumstances. This paper provides an explanation to this puzzle. We consider two modes of lending, group and individual lending, and for each mode we characterize the optimal lending and supervisory contracts when a staff member (a supervisor) can embezzle borrowers' repayments by misrepresenting realized returns. We identify the main trade-off between the insurance gain and the cost of controlling the supervisor's misbehavior. We also find that group lending dominates individual lending either by providing more insurance or by saving audit costs.
\end{abstract}

JEL Code: O16, D82, G20

Key words: Microfinance, Repayment, Contract, Group Lending, Embezzlement, Insurance.

*We thank seminar participants at Universidad Carlos III, Universitat Pompeu Fabra, Université de Toulouse, ASSET 05 (Crete) and FEMES 06 (Beijing). We also thank Martin Besfamille, Bruno Biais, Vicente Cuñat, Xavier Freixas, Patrick Rey, Jean-Charles Rochet, Joel Shapiro and two anonymous referees for helpful comments. The first author gratefully acknowledges financial support from the Spanish government under SEJ2006-09993/ECON.

†Toulouse School of Economics and CEPR. dohshin.jeon@gmail.com

†Università degli Studi di Firenze, Italy. domenico.menicucci@dmd.unifi.it 


\section{Introduction}

The remarkable success of microfinance programs in making loans to (and recovering them from) poor people has received world-wide attention and generated a global microfinance movement which has been growing rapidly. According to the report from the Microcredit Summit Campaign, as of December 31, 2007, 3,552 microcredit institutions reported reaching $154,825,825$ clients, $106,584,679$ of whom were among the poorest when they took their first loan. ${ }^{1}$ The original ideas of microfinance are from Muhammad Yunus, the founder of the Grameen bank and Nobel peace prize laureate in 2006, who started making small loans to groups of poor people in rural areas in Bangladesh in the 1970s. Today the Grameen bank is a large financial organization: according to the monthly report of February 2009, it disbursed a total of $\$ 7,776.55$ million since inception to about 7.51 millions borrowers with a loan recovery rate of approximately 97.93 percent. $^{2}$

There exists a large economic literature on microfinance and most of it focuses on how group lending affects adverse selection (Ghatak, 1999, Armendáriz de Aghion and Gollier 2000, Laffont and N'Guessan 2000, Laffont, 2003), moral hazard in terms of loan repayment (Besley and Coate, 1995, Armendáriz de Aghion 1999, Sadoulet 2000, Rai and Sjöström, 2004), and moral hazard before return realization in terms of work incentives (Stiglitz 1990, Varian 1990, Conning 1999, Che 2002, Laffont and Rey, 2003). ${ }^{3}$ Despite the variety of the issues that these papers examine, most of them, with a few exceptions mentioned later on, consider only borrowers' incentives and do not study the incentive issues of the bank staff managing the loans. Furthermore, all papers studying the optimal lending contracts find that state-contingent repayments are optimal, where a state refers to a realized return of a borrower's project. This finding is in stark contrast with the practice of the classic Grameen bank, which specifies a rigid repayment schedule that does not depend on the realization of the state of nature. ${ }^{4}$ The Grameen bank's practice is very puzzling since it means that poor borrowers of the Grameen bank make their payments even under hard circumstances. This paper tries to explain the puzzle.

\footnotetext{
${ }^{1}$ See https://promujer.org/empowerment/dynamic/our_publications_5_Pdf_EN_SOCR2009\%20English.pdf accessed on Feb. 8, 2010.

${ }^{2}$ See http://www.grameen-info.org/index.php?option=com_content\&task=view\&id=453\&Itemid=527

${ }^{3}$ See Ghatak and Guinnane (1999) and Morduch (1999) for surveys. The book written by Armendáriz de Aghion and Morduch (2005) also reviews some recent papers that focus on other issues such as dynamic incentives, competition, the use of collateral, etc.

${ }^{4}$ Yunus (1998, p.110) describes the repayment mechanism of the Grameen bank as: (i) one year loan (ii) equal weekly installments (iii) repayment starts one week after the loan etc. In section 7, we discuss the transition from Grameen I (the classic Grameen) to Grameen II.
} 
Whether a microfinance institution should use a state-contingent loan or not is an extremely important issue since a state-contingent loan can provide insurance to borrowers by linking repayments to the success or failure of their projects. ${ }^{5}$ However, the spectacular growth of microfinance institutions raises the issue of staff's quality and their misbehavior. ${ }^{6}$ In particular, when a loan is state-contingent, a staff member managing the loan might manipulate his ${ }^{7}$ report to the lender in order to embezzle some repayments. In this paper, we study the optimal lending contract and the optimal supervisory contract when a staff member (called a supervisor) can embezzle repayments by misrepresenting the realized state. More precisely, we identify the condition determining whether the optimal repayment is state-contingent or not and analyze how the mode of lending (group versus individual lending) affects the condition.

Given that embezzlement and corruption are very frequent in most organizations in underdeveloped countries, ${ }^{8}$ incentive schemes in microfinance institutions should be designed to reduce the scope for such misconduct of staff. In particular, in the case of microfinancing programs in poor countries, most borrowers are illiterate and means of transportation are primitive; therefore, they get informed about the loan conditions exclusively through the bank staff member who visits their villages to collect repayments. This creates significant scope for the staff's misconduct and embezzlement, as is documented by Bornstein $(1996)^{9}$ and Mknelly and Kevane (2002). ${ }^{10}$

We consider a simple model of hierarchy: there are a lender, a supervisor and two borrowers. The lender maximizes the borrowers' payoffs subject to her own break-even constraint. The supervisor must check the success or failure of the project undertaken by each borrower and collect the repayments. We assume that the supervisor can discover the

\footnotetext{
${ }^{5}$ For instance, the Bank for Agriculture and Agricultural Cooperatives (BAAC) in Thailand uses state-contingent repayments in that a nonrepayment can be rescheduled if it is due to force majeur, but is penalized otherwise. (Townsend and Yaron, 2001, p.36). See also the discussion of Grameen II in section 7 .

${ }^{6}$ Bazoberry (2001, p.13) describes six unauthorized activities that staff members of some microfinance organizations in Bolivia engaged in, such as creation of "ghost" loans to hide the fact that goals are not met, utilization of inactive saving accounts to pay for outstanding debts, etc. Bond and Rai (2002) give several examples of supervisor frauds around the world.

${ }^{7}$ We use "she" for the lender, and "he" for the staff member (i.e., the supervisor) and for a borrower.

${ }^{8}$ For instance, Angolan officials are accused of embezzling 10 percent of the country's GDP. (Fantaye, 2004, p.173).

${ }^{9}$ Bornstein writes about embezzlement in the early period of the Grameen bank (pp. 169-174).

${ }^{10}$ According to Mknelly and Kevane (2002), embezzlement occurs because illiterate borrowers cannot maintain their account books.
} 
return realization by visiting the borrowers' village and can enforce repayments. ${ }^{11}$ In other words, we assume that a borrower is able to repay the loan even when the project fails: although this is a significant departure from the standard assumption in the microfinance literature, we would like to emphasize that it is consistent with the $98 \%$ repayment rate in the Grameen bank. In addition, we suppose that a borrower's marginal cost of paying back one unit of money is higher when his project fails than when it succeeds. Therefore, if the supervisor were honest, the lender would provide full insurance to the borrowers by recovering all financing cost only through repayments upon success.

The lender can design either a state non-contingent lending contract in which a borrower makes the same payment regardless of the realization of project returns, or a statecontingent contract in which the repayment depends on the realization of the return(s): in the case of individual lending, a borrower's repayment depends only on his own return while in the case of group lending, a borrower's repayment can depend also on the return of the other borrower. If the lender uses a state-contingent loan, the supervisor has some discretion in that, for instance, when a project succeeded, he can report that the project failed and embezzle the difference between the payment upon success and the payment upon failure. The lender can use incentive pay and/or audit to induce the supervisor to behave well, but the supervisor is protected by limited liability: in case auditing reveals that embezzlement occurred, the lender can recover the stolen money and fire the supervisor without paying any wage, but the supervisor is not liable for a further fine. ${ }^{12}$

We first consider group lending. In this case, the optimal lending contract always provides some insurance by requiring that only the successful borrower pays when only one project succeeds. Furthermore, the aggregate repayment is constant (i.e., no discretion of the supervisor) as long as at least one project succeeds. Let the supervisor's discretion refer to the difference between the aggregate repayment when there is at least one successful project and the one when both projects fail. The optimal supervisory contract for a given level of discretion is such that it is optimal to use incentive pay only (respectively, audit only) when the amount of discretion is smaller (respectively, larger) than a threshold level. Optimization with respect to the amount of discretion reveals that zero

\footnotetext{
${ }^{11}$ The enforcement can be done through (i) pecuniary punishment such as denial of future loan (chapter 5.2 of Armendáriz de Aghion and Morduch, 2005) and seizure of income or assets (Besley and Coate, 1995) or (ii) non-pecuniary punishment of being 'hassled' by the bank (Besley and Coate, 1995).

${ }^{12}$ Note that with unlimited liability, the agency problem can be solved at almost zero cost either by imposing a fine large enough when embezzlement is discovered or by "selling the firm to the supervisor" and making the supervisor a residual claimant. We do not think that any of the two is a realistic solution to the problem.
} 
discretion (respectively, maximum discretion) is optimal when the amount of discretion is smaller (respectively, larger) than the threshold. Therefore, the optimal lending contract involves either zero or the maximum discretion. In the latter case, each borrower makes a payment only when his project succeeds but the lender should conduct an audit when the supervisor reports that both projects failed. Hence, the optimal contract is state non-contingent when the audit cost is larger than the borrowers' gain from full insurance.

Furthermore, in the case of individual lending, we find that the optimal lending contract is also determined by a similar trade-off between the insurance gain and the cost of controlling misbehavior of the supervisor. However, conditional on that the optimal contract is state-contingent, the lender finds it optimal to use audit only (respectively, a mix of audit and incentive pay) if the audit cost is lower (respectively, higher) than a threshold.

When we compare group lending with individual lending, we find that the former is strictly preferred to the latter for two reasons. First, in the case of state non-contingent loan, group lending provides insurance when only one project fails. Second, in the case of state-contingent loan, group lending reduces the audit cost since audit occurs only when both projects fail in the case of group lending while audit occurs when at least a project fails in the case of individual lending. Therefore, group lending can be regarded as an optimal response to the embezzlement problem. However, if the borrowers can sign a side-contract for mutual insurance before return realization, we show that the outcome of the optimal non-contingent contract under group lending can be achieved also under individual lending.

Our paper is closely related to the literature on collusion between a supervisor and an agent in mechanism design theory (Tirole 1986, Laffont and Tirole 1991, Kofman and Lawarrée 1993 and Faure-Grimaud, Laffont and Martimort 2003). This literature derives the optimal collusion-proof contract when the supervisor can manipulate the information he reports to the principal about the agent's type in exchange for a bribe. We do not consider collusion ${ }^{13}$ but focus on the supervisor's incentive to unilaterally manipulate his

\footnotetext{
${ }^{13}$ Given that collection of repayments in the Grameen bank is done in a village meeting which all the members (about 40 to 60 people) of a center should attend, a "naked" collusion at the center meeting among a staff member and all the borrowers of the center seems to be unlikely. In addition, collusion with a subset of borrowers needs to be organized and enforced without documents (since most borrowers are illiterate) and without being noticed by other borrowers. On the contrary, embezzlement does not require such an organization and enforcement. For these reasons, embezzlement seems like a more natural issue to focus on than collusion. However, our model can be used to deal with collusion with minor modifications and our insight is applicable to collusion issue as well (see section 5, Jeon-Menicucci, 2009).
} 
report to embezzle payments.

Our paper is related to the literature on costly state verification (Townsend 1979, Gale and Hellwig 1985), in particular the one on delegated monitoring (Diamond 1984), as the lender can conduct an audit to verify the realized returns reported by the supervisor. However, there are three major differences. First, in our model, the presence of an intermediary is given, which is natural in the case of the Grameen bank, while delegation to an intermediary endogenously arises as the optimal structure in Diamond (1984). Second, since we assume that the two borrowers know the realized return of each other's project, if the lender directly deals with the borrowers without mediation of the supervisor, the lender can achieve the first-best outcome by using cross-reporting even when each borrower can manipulate his report. ${ }^{14}$ Third, while the literature on costly state verification assumes that a borrower cannot repay the loan in some states of nature and derives the optimality of a state-contingent contract, we assume that a borrower is able to repay the loan even when the project fails and study the trade-off between a state-contingent loan and a state non-contingent one.

In the microfinance literature, only a few papers (Conning 1999 and Aubert, Janvry and Sadoulet 2005) consider a hierarchy but none of them considers embezzlement. For instance, Conning (1999) studies both a borrower's incentive to divert funds and a staff member's incentive to monitor the former's misbehavior but assumes that the realized return is common knowledge, as many papers on microfinance do.

The paper is organized as follows. Section 2 presents the model, section 3 analyzes group lending, section 4 analyzes individual lending and section 5 compares the two. Section 6 considers individual lending with mutual insurance and section 7 gives concluding remarks and discusses the transition from Grameen I to Grameen II. All proofs are gathered in Appendix.

\section{Model}

We consider a hierarchy composed of a lender, a supervisor and two borrowers. The two borrowers live in the same village. Each borrower borrows one unit of money from the lender and invests it in a project. The lender is risk neutral and designs the contracts to maximize the borrowers' payoffs under her own break-even constraint. To break even, she needs to recover the opportunity cost of the loan $2 \rho(>2)$ plus the wage bill paid to the supervisor and the cost of audit (if there is any). For simplicity, we assume that

\footnotetext{
${ }^{14}$ The proof is available from the authors upon request.
} 
the return of each project is identically and independently distributed. Let $Y$ denote the return from a borrower's project: with probability $p \in(0,1)$, the project succeeds and $Y=Y_{S}>0$; with probability $1-p$, it fails and $Y=Y_{F}=0$.

We distinguish a group lending contract from an individual lending contract. We assume that the borrowers know the realized return of each other's project. A group lending contract takes the form $\left\{r_{S S}, r_{S F}, r_{F S}, r_{F F}\right\}$ where, for instance, $r_{S F}$ is the payment that a borrower whose project succeeded has to make when the other borrower's project failed. An individual lending contract takes the form $\left\{r_{S}, r_{F}\right\}$ and a borrower's repayment depends only on the return realization of his own project. Without loss of generality, we assume $r_{i j} \geq 0$ for $i, j=S, F$ and $r_{i} \geq 0$ for $i=S, F{ }^{15}$

The lender does not ask for any collateral. In the case of failure, however, a borrower is still able to generate the amount of cash $r>0$, but in order to do so he must reduce his consumption (or sell his assets, or withdraw his children from school, borrow money from local money lenders charging usurious interest rates $\left.{ }^{16}\right)$. This is costly in the following sense: generating $r$ units of money in state $F \operatorname{costs} \psi(r)$ to the borrower, with $\psi(0)=0$, $\psi^{\prime}(r)>1$ and $\psi^{\prime \prime}(r) \geq 0$ for any $r>0$; hence, $\psi(r)>r$ for $r>0$. Let $U(Y, r)$ denote a borrower's utility. We assume:

$$
\begin{array}{cc}
U(Y, r)=Y-r & \text { if } Y-r \geq 0 \\
U(Y, r)=-\psi(r-Y) & \text { if } Y-r<0
\end{array}
$$

Thus, a borrower's marginal utility of one unit of money is 1 if $Y-r \geq 0$, but it is larger than 1 if $Y-r<0$. This decreasing marginal utility of money makes the borrower risk averse. We say that the borrowers are fully insured if $r_{F}=0$ and $r_{S} \leq Y_{S}$ in the case of individual lending (if $r_{F j}=0$ and $r_{S j} \leq Y_{S}$ for $j=S, F$ in the case of group lending); then, each borrower makes a payment to the lender only in state $S$ and the marginal utility from additional money is equal to one regardless of the realized state. When $r_{S} \leq Y_{S}$, a borrower's expected payoff upon accepting an individual lending contract is given by:

$$
p\left(Y_{S}-r_{S}\right)-(1-p) \psi\left(r_{F}\right) .
$$

The supervisor is the intermediary between the lender and the borrowers. He has the task to observe and report the return realization of each project to the bank, and to collect the borrowers' repayments. We assume that the supervisor observes the realized

\footnotetext{
${ }^{15}$ We obtain the same results even though $r_{i j}$ or $r_{i}$ can be negative (because negative repayments do not provide more insurance than zero repayments), but considering this possibility makes the proofs longer.

${ }^{16}$ For instance, Jain and Mansuri (2003) provide evidence of microfinance members borrowing money from local lenders.
} 
state by visiting each borrower and can enforce the repayment. Since collecting the repayments anyway requires him to visit the borrowers, we assume that his cost of visiting the borrowers is zero for simplicity. A supervisory contract specifies a wage contingent on the states he reports: let $w_{n}$ represent the supervisor's wage when he reports that $n$ number of projects succeeded, with $n \in\{0,1,2\}$. We suppose that the supervisor's wage cannot be lower than a certain minimum wage $\underline{w} \geq 0$, which is the supervisor's reservation utility: ${ }^{17}$ hence, his participation constraint, i.e. $w_{n} \geq \underline{w}$, is trivially satisfied. For simplicity, we assume $\underline{w}=0 .{ }^{18}$

We focus on the moral hazard of the supervisor, who can misrepresent the realized states to the lender. For instance, if $r_{S S}-r_{F F}>0$, by reporting $n=0$ when the true $n$ is 2 the supervisor can embezzle $2\left(r_{S S}-r_{F F}\right)$. The lender can audit the actual payments made by the borrowers at a cost of $k(>0)$ : Since both borrowers live in the same village, the cost of audit does not depend on whether the lender audits the payment of one borrower or those of both borrowers. ${ }^{19}$ When cheating is discovered, the lender can recover the embezzled repayment, fire the supervisor, and refuse to pay him any wage. However, we assume that the lender cannot impose any further fine on him since the supervisor is protected by limited liability. ${ }^{20}$ A supervisory contract is represented by $\left\{w_{n}, q_{n}\right\}_{n=0,1,2}$, where $q_{n}$ is the probability of conducting an audit when the supervisor reports that $n$ number of projects succeeded. The supervisor is assumed to be risk-neutral.

A grand-contract is composed of a lending contract $\left\{r_{S S}, r_{S F}, r_{F S}, r_{F F}\right\}$ or $\left\{r_{S}, r_{F}\right\}$ and a supervisory contract $\left\{w_{n}, q_{n}\right\}_{n=0,1,2}$. We assume that the lender makes a take-it-or-leaveit offer to both the supervisor and the borrowers. Let $\Delta \equiv r_{S}-r_{F}, \Delta_{1} \equiv r_{S F}+r_{F S}-2 r_{F F}$ and $\Delta_{2} \equiv 2 r_{S S}-r_{S F}-r_{F S}$. We have two observations:

Observation 1: The set of individual lending contracts is a strict subset of the set of group lending contracts since the former is equal to the set of group lending contracts that satisfy $r_{S S}=r_{S F}=r_{S}$ and $r_{F S}=r_{F F}=r_{F}$ (equivalently, $\Delta_{1}=\Delta_{2}=\Delta$.)

Observation 2: The first-best outcome is such that $w_{n}=0, q_{n}=0$ for $n=0,1,2$

\footnotetext{
${ }^{17}$ It is common to assume that the minimum wage is defined with respect to the reservation utility: Laffont and Martimort (2002, section 4.8.1).

${ }^{18}$ Conning (1999) also assumes $\underline{w}=0$. See Jeon-Menicucci (2009) for the analysis of $\underline{w} \geq 0$.

${ }^{19}$ Since the auditor can easily find out the actual amount paid by a borrower as long as he visits him, the main cost of audit is the cost of visiting the village and the marginal cost of visiting one more borrower in the same village is negligible. Even if we assume that the cost of auditing two borrowers is $2 k$, our main result would qualitatively hold.

${ }^{20}$ See footnote 12 for justification.
} 
and each borrower makes a payment (equal to $\rho$ in expectation) only when his project is successful. If the supervisor is honest, it is possible to achieve the first-best with individual lending (and, a fortiori, with group lending) by setting $p r_{S}=\rho, r_{F}=0$ and $w_{n}=0, q_{n}=0$ for $n=0,1,2$.

For expositional facility, we define two kinds of lending contracts, depending on whether or not the contract is state-contingent, and two kinds of supervisory contracts.

Definition 1: An individual lending contract is said to be state non-contingent (respectively, state-contingent) if $\Delta=0$ (respectively, otherwise). A group lending contract is state non-contingent (respectively, state-contingent) if $\Delta_{1}=\Delta_{2}=0$ (respectively, otherwise).

Definition 2: A supervisory contract with $w_{2}=w_{1}=w_{0}$ and $q_{n}>0$ for some $n=$ $0,1,2$ is called a supervisory contract with stick. A supervisory contract with $q_{2}=q_{1}=q_{0}$ and $\left(w_{2}-w_{1}\right) \Delta_{2}>0$ and/or $\left(w_{1}-w_{0}\right) \Delta_{1}>0^{21}$ is called a supervisory contract with carrot.

In a state non-contingent lending contract, the supervisor has no discretion since the total payments of the borrowers are constant and do not depend on the realized states. When a lending contract is state-contingent, the supervisor has some discretion (represented by $\Delta_{n}>0$ or $\Delta>0$ ) and the lender can use either stick (i.e. audit) or carrot (i.e. incentive pay) or a mix of both in order to induce the supervisor to behave well.

We make the following assumption:

A1: (i) $p Y_{S}>\rho+(1-p) \min \left\{\psi(\rho)-\rho, \frac{1+p}{2} k\right\}$ and (ii) $Y_{S} \geq \Delta_{1}^{\max }$, where $\Delta_{1}^{\max }$ is defined by

$$
\Delta_{1}^{\max }=\frac{2 \rho+(1-p)^{2} k}{p(2-p)} .
$$

Both A1(i) and A1(ii) require that $Y_{S}$ be sufficiently large. Precisely, A1(i) implies that the NPV of the project is positive at the optimal contract, for both group lending and individual lending. A1(ii) simplifies our analysis of the optimal group lending contract in that $r_{F S}=0$ becomes optimal.

\footnotetext{
${ }^{21}$ Obviously, in the case of individual lending, $\left(w_{2}-w_{1}\right) \Delta>0$ and/or $\left(w_{1}-w_{0}\right) \Delta>0$ replaces $\left(w_{2}-w_{1}\right) \Delta_{2}>0$ and/or $\left(w_{1}-w_{0}\right) \Delta_{1}>0$.
} 


\section{Group lending}

In this section we consider group lending. By the revelation principle, there is no loss of generality in restricting our attention to direct and truthful revelation mechanisms. Therefore, the following incentive constraints for the supervisor to truthfully reveal the states need to be satisfied:

$$
\left(\mathrm{IC}_{n \widehat{n}}\right) \quad w_{n} \geq\left(1-q_{\widehat{n}}\right)\left[R(n)-R(\widehat{n})+w_{\widehat{n}}\right] \quad \text { for } \quad(n, \widehat{n}) \in\{0,1,2\}^{2},
$$

where $R(2) \equiv 2 r_{S S}, R(1) \equiv r_{S F}+r_{F S}, R(0) \equiv 2 r_{F F}$ are the aggregate payments of borrowers in different states. Recall that if the embezzlement is discovered, then the supervisor receives nothing as he loses both the embezzled money and his wage. The lender's break-even constraint is given by

$$
\begin{gathered}
(B E) \quad p^{2} 2 r_{S S}+2 p(1-p)\left(r_{S F}+r_{F S}\right)+(1-p)^{2} 2 r_{F F} \\
\geq 2 \rho+p^{2}\left(w_{2}+k q_{2}\right)+2 p(1-p)\left(w_{1}+k q_{1}\right)+(1-p)^{2}\left(w_{0}+k q_{0}\right),
\end{gathered}
$$

where the right hand side represents the total financing cost of the loans. The lender's program, denoted by $\left(L^{G}\right)$, is defined as follows:

$$
\begin{aligned}
& \max p^{2}\left(2 Y_{S}-2 r_{S S}\right)+2 p(1-p)\left(Y_{S}-r_{S F}-\psi\left(r_{F S}\right)\right)-(1-p)^{2} 2 \psi\left(r_{F F}\right) \\
& \text { with respect to } r_{S S}, r_{S F}, r_{F S}, r_{F F}, \text { and }\left\{w_{n}, q_{n}\right\}_{n=0,1,2} \\
& \qquad \begin{array}{l}
\text { subject to } \\
\qquad(3), \quad(B E), \quad r_{i j} \geq 0 \text { for } i, j=S, F, \quad w_{n} \geq 0 \text { for } n=0,1,2 .
\end{array}
\end{aligned}
$$

Note that in the objective function of $\left(L^{G}\right)$ we assume $r_{S F} \leq Y_{S}$ and $r_{S S} \leq Y_{S}$, which in the proof of Proposition 1 we verify to be satisfied under A1. In what follows, we identify the optimal contract by focusing on the case with $\Delta_{1} \geq 0$ and $\Delta_{2} \geq 0$, but at the end of this section, in Lemma 3, we show that the optimal contract satisfies $\Delta_{1} \geq 0$ and $\Delta_{2} \geq 0$.

Our next lemma presents one important property of group lending:

Lemma 1 In the case of group lending, the optimal $r_{F S}$ is equal to zero if $Y_{S}$ is sufficiently large.

Lemma 1 says that when only one borrower is successful, it is optimal that the unsuccessful borrower pays nothing: $r_{F S}=0$. The reason is that requiring the unsuccessful 
borrower to pay a positive amount forces him to reduce his consumption, which is more costly than requiring the successful borrower to pay for both. Therefore, group lending provides borrowers with insurance when only one project is successful. Clearly, the resulting $r_{S F}$ is relatively high and this approach is viable only if the successful borrower has enough money to pay $r_{S F}$; the proof of Proposition 1 shows that $r_{S F} \leq Y_{S}$ holds in the optimal contract under A1.

Given $\Delta_{1} \geq 0$ and $\Delta_{2} \geq 0$, it is intuitive that the supervisor has no incentive to report a state $\widehat{n}$ larger than $n$. Accordingly, we consider a relaxed problem $\left(L r^{G}\right)$ in which the upward incentive constraints $\left(\mathrm{IC}_{02}\right),\left(\mathrm{IC}_{01}\right),\left(\mathrm{IC}_{12}\right)$ are neglected and only the following downward incentive constraints are imposed:

$$
\left\{\begin{array}{c}
\left(\mathrm{IC}_{21}\right) \quad w_{2} \geq\left(1-q_{1}\right)\left(\Delta_{2}+w_{1}\right) ; \\
\left(\mathrm{IC}_{20}\right) \quad w_{2} \geq\left(1-q_{0}\right)\left(\Delta_{2}+\Delta_{1}+w_{0}\right) ; \\
\left(\mathrm{IC}_{10}\right) \quad w_{1} \geq\left(1-q_{0}\right)\left(\Delta_{1}+w_{0}\right) .
\end{array}\right.
$$

In the proof of Proposition 1 we show that $\left(\mathrm{IC}_{02}\right),\left(\mathrm{IC}_{01}\right),\left(\mathrm{IC}_{12}\right)$ are satisfied in the solution of the relaxed problem, thus the solution of $\left(L r^{G}\right)$ is also a solution of $\left(L^{G}\right)$.

The next lemma establishes some properties of the solution of $\left(L r^{G}\right)$.

Lemma 2 The solution to the relaxed problem $\left(\mathrm{Lr}^{G}\right)$ is such that

(i) (BE) binds, $w_{0}=0, q_{1}=q_{2}=0$, and $\Delta_{2}=0$;

(ii) all the constraints in (4) bind, hence $w_{1}=w_{2}=\left(1-q_{0}\right) \Delta_{1}$.

The results of this lemma are quite relevant for the shape of the optimal contract, but are also pretty intuitive. First, there is no reason to give any reward to the supervisor when he reports $n=0$ : he is transferring the lowest possible amount of money to the lender, and so $w_{0}=0$. Second, when the supervisor reports $n=2$ there is no reason to conduct an audit: he is transferring the highest possible amount of money to the lender, and so $q_{2}=0$. Third, it pays to have $\Delta_{2}=0$ because $\Delta_{2}>0$ generates some embezzlement opportunities for the supervisor, and by reducing $\Delta_{2}$, and simultaneously increasing $\Delta_{1}$, it is possible to reduce the cost of auditing in states $F S$ and $S F$ and/or the wage bill (notice that in view of Lemma 1, an increase in $\Delta_{1}$ does not increase the payment of an unsuccessful borrower). Finally, $\Delta_{2}=0$ implies $w_{1}=w_{2}$ and that no auditing occurs in states $S F$ and $F S$.

As a consequence of Lemma 2 , only $q_{0}$ and $\Delta_{1}$ need to be determined in order to find the solution to $\left(L r^{G}\right)$. To this purpose, we perform a two-step analysis: we first find the optimal $q_{0}$ for any given $\Delta_{1} \geq 0$, and then we identify the optimal $\Delta_{1}$. 
Given an arbitrary value of $\Delta_{1} \geq 0, q_{0}$ affects only the total financing cost, which is $2 \rho+p^{2}\left(1-q_{0}\right) \Delta_{1}+2 p(1-p)\left(1-q_{0}\right) \Delta_{1}+(1-p)^{2} k q_{0}$. Since this cost is linear in $q_{0}$, it is straightforward to find $q_{0}$ which minimizes the cost: After defining $\bar{\Delta}_{1} \equiv \frac{(1-p)^{2}}{p(2-p)} k$, we find that the minimum is achieved at $q_{0}=0$ if $\Delta_{1} \leq \bar{\Delta}_{1}$ (respectively, at $q_{0}=1$ if $\Delta_{1}>\bar{\Delta}_{1}$ ). In the first case the optimal supervisory contract uses carrot only such that $q_{0}=0$ and $w_{2}=w_{1}=\Delta_{1}$. In the second case, $\Delta_{1}$ is large enough and this makes the carrot approach too expensive: the optimal supervisory contract uses stick only such that $q_{0}=1$ and $w_{2}=w_{1}=0$. Let $C^{G}\left(\Delta_{1}\right)$ denote the total financing cost when the supervisory contract is chosen optimally:

$$
C^{G}\left(\Delta_{1}\right)=\left\{\begin{array}{cc}
2 \rho+p(2-p) \Delta_{1} & \text { if } \Delta_{1} \in\left[0, \bar{\Delta}_{1}\right] \\
2 \rho+(1-p)^{2} k & \text { if } \Delta_{1}>\bar{\Delta}_{1} .
\end{array}\right.
$$

In order to derive the optimal lending contract, we recall that $r_{F S}=0$ (by Lemma 1) and $\Delta_{2}=0$ [by Lemma 2(i)], which implies $r_{S F}=2 r_{S S}=\Delta_{1}+2 r_{F F}$. Therefore, the lender's program can be written as

$$
\begin{gathered}
\max _{\Delta_{1} \geq 0, r_{F F} \geq 0} 2 p Y_{S}-p(2-p)\left(2 r_{F F}+\Delta_{1}\right)-(1-p)^{2} 2 \psi\left(r_{F F}\right) \\
\text { subject to } \quad(B E) \quad 2 r_{F F}+p(2-p) \Delta_{1}=C^{G}\left(\Delta_{1}\right)
\end{gathered}
$$

Consider first the carrot regime, that is $\Delta_{1} \in\left[0, \bar{\Delta}_{1}\right]$. Then (BE) is equivalent to $r_{F F}=\rho$, and increasing $\Delta_{1}$ above zero has the only effect of increasing the financing cost (through increased wages) without improving any insurance provision. Therefore it is optimal to choose $\Delta_{1}=0$ in the carrot regime; the resulting contract does not leave any embezzlement opportunity and therefore neither carrot nor stick is necessary.

Consider now the stick regime, that is $\Delta_{1} \geq \bar{\Delta}_{1}$. Then (BE) is equivalent to

$$
r_{F F}=\rho+\frac{1}{2}(1-p)^{2} k-\frac{1}{2} p(2-p) \Delta_{1}\left(\equiv r_{F F}\left(\Delta_{1}\right)\right) .
$$

Since $r_{F F}\left(\Delta_{1}\right)$ must be non-negative and decreases in $\Delta_{1}$ with $r_{F F}\left(\Delta_{1}^{\max }\right)=0\left[\Delta_{1}^{\max }\right.$ is introduced in (2)], we need to maximize

$$
2 p Y_{S}-p(2-p)\left[2 r_{F F}\left(\Delta_{1}\right)+\Delta_{1}\right]-(1-p)^{2} 2 \psi\left[r_{F F}\left(\Delta_{1}\right)\right]
$$

with respect to $\Delta_{1} \in\left[\bar{\Delta}_{1}, \Delta_{1}^{\max }\right]$. Here an increase in $\Delta_{1}$ does not affect the total financing cost (which is constant) but shifts the payments of each borrower from the state $F F$ to other states without altering each borrower's expected payment. Since increasing $\Delta_{1}$ 
provides more insurance without affecting the financing cost, it is optimal to choose the highest $\Delta_{1}$, that is $\Delta_{1}=\Delta_{1}^{\max }$, to provide full insurance (i.e. $r_{F F}=0$ ).

The above analysis reveals that the optimal lending contract is either a state-contingent contract with $2 r_{S S}=r_{S F}+r_{F S}>2 r_{F F}=0$ or a state non-contingent contract with $2 r_{S S}=r_{S F}+r_{F S}=2 r_{F F}$. Summarizing, we have:

Proposition 1 Consider group lending. Under A1,

(i) the optimal grand contract is the best contract between the two following contracts:

a. A state non-contingent lending contract $\left\{2 r_{S S}=2 r_{F F}=r_{S F}=2 \rho, r_{F S}=0\right\}$ with $\left\{q_{0}=q_{1}=q_{2}=0, w_{0}=w_{1}=w_{2}=0\right\}$;

b. A state-contingent lending contract providing full insurance $\left\{r_{F S}=r_{F F}=0\right.$, $\left.r_{S F}=2 r_{S S}=\frac{2 \rho+(1-p)^{2} k}{p(2-p)}\right\}$ combined with audit in state $F F:\left\{q_{0}=1, q_{1}=q_{2}=0\right.$, $\left.w_{0}=w_{1}=w_{2}=0\right\}$.

(ii) The state non-contingent contract is optimal if and only if $k \geq 2[\psi(\rho)-\rho]$.

A state non-contingent contract provides insurance only when at least one project succeeds, and thus each borrower bears the cost of reducing his own consumption only when both projects fail. On the contrary, a state-contingent contract provides insurance for all states of the world, but auditing is necessary when both projects fail in order to deter embezzlement. Therefore, the state-contingent contract is optimal when the audit cost $(1-p)^{2} k$ is larger than the gain from providing both borrowers with full insurance, $(1-p)^{2} 2[\psi(\rho)-\rho]$, as Proposition 1 (ii) states.

Finally, the following lemma shows that there is no loss of generality in restricting attention to contracts with $\Delta_{1} \geq 0$ and $\Delta_{2} \geq 0$ as we have done in this section. ${ }^{22}$

Lemma 3 In the case of group lending, under A1, the optimal lending contract satisfies $\Delta_{1} \geq 0$ and $\Delta_{2} \geq 0$.

\section{Individual lending}

In the case of individual lending we have $r_{S S}=r_{S F}=r_{S}$ and $r_{F S}=r_{F F}=r_{F}$, which implies $\Delta_{1}=\Delta_{2} \equiv \Delta$. In order to see the effects of this restriction, we recall that under group lending it is optimal to set $r_{F S}=0$ (Lemma 1). Under individual lending, however, $r_{F S}=0$ implies $r_{F F}=0$ and therefore, for instance, the state non-contingent group

\footnotetext{
${ }^{22}$ The lemma is stated here because its proof is easier to read with the knowledge of the analysis for the case with $\Delta_{1} \geq 0$ and $\Delta_{2} \geq 0$.
} 
lending contract described by Proposition 1(i)a is not feasible. Notice also that while it is always optimal to set $\Delta_{2}=0$ under group lending [Lemma 2(i)], no similar result holds with individual lending because $\Delta_{2}=0$ implies $\Delta_{1}=0$. In particular, we can show that there is no loss of generality in considering only the case $\Delta \geq 0$.

Lemma 4 The optimal contract under individual lending is such that $\Delta \geq 0$.

The intuition for this result is that if $r_{S}<r_{F}$, then increasing the payment in state $S$ and decreasing the payment in state $F$ without modifying the expected payment relaxes the incentive constraints for the supervisor and increases the borrower's expected utility given that $\psi^{\prime}(r)>1$.

The lender's problem under individual lending is defined as

$$
\begin{gathered}
\max 2\left[p Y_{S}-p r_{S}-(1-p) \psi\left(r_{F}\right)\right] \\
\text { with respect to } r_{S} \geq 0, r_{F} \geq 0, \text { and }\left\{w_{n}, q_{n}\right\}_{n=0,1,2}
\end{gathered}
$$

subject to

$$
\begin{gathered}
\left(\mathrm{IC}_{n \widehat{n}}\right) \quad w_{n} \geq\left(1-q_{\widehat{n}}\right)\left[\Delta(n-\widehat{n})+w_{\widehat{n}}\right] \quad \text { for } \quad(n, \widehat{n}) \in\{0,1,2\}^{2}, \\
(B E) \quad 2 p r_{S}+2(1-p) r_{F} \\
\geq 2 \rho+p^{2}\left(w_{2}+k q_{2}\right)+2 p(1-p)\left(w_{1}+k q_{1}\right)+(1-p)^{2}\left(w_{0}+k q_{0}\right) \\
w_{n} \geq 0 \text { for } n=0,1,2
\end{gathered}
$$

Also in this setting we consider the relaxed problem in which the upward incentive constraints $\left(\mathrm{IC}_{02}\right),\left(\mathrm{IC}_{01}\right),\left(\mathrm{IC}_{12}\right)$ are neglected, and then we verify that the solution to the relaxed problem is the solution to the complete problem. The incentive constraints for the relaxed problem are

$$
\left\{\begin{array}{c}
\left(\mathrm{IC}_{21}\right) \quad w_{2} \geq\left(1-q_{1}\right)\left(\Delta+w_{1}\right) \\
\left(\mathrm{IC}_{20}\right) \quad w_{2} \geq\left(1-q_{0}\right)\left(2 \Delta+w_{0}\right) \\
\left(\mathrm{IC}_{10}\right) \quad w_{1} \geq\left(1-q_{0}\right)\left(\Delta+w_{0}\right)
\end{array}\right.
$$

We apply again a two-step procedure as follows: given any $\Delta \geq 0$, first we find the optimal supervisory contract by minimizing the total financing cost. Then this result is used to find the optimal $\Delta$. Next lemma describes the optimal supervisory contract as a function of $\Delta$. 
Lemma 5 For any given $\Delta \geq 0$, the optimal supervisory contract is described as follows contract $\alpha:\left(q_{0}, q_{1}, q_{2}\right)=(0,0,0)$ and $\left(w_{0}, w_{1}, w_{2}\right)=(0, \Delta, 2 \Delta) \quad$ if $\quad \Delta \leq \frac{(1-p)^{2}}{p(2-p)} k$;

contract $\beta:\left(q_{0}, q_{1}, q_{2}\right)=(1,0,0)$ and $\left(w_{0}, w_{1}, w_{2}\right)=(0,0, \Delta) \quad$ if $\quad \frac{(1-p)^{2}}{p(2-p)} k<\Delta \leq \frac{2(1-p)}{p} k$; contract $\gamma:\left(q_{0}, q_{1}, q_{2}\right)=(1,1,0)$ and $\left(w_{0}, w_{1}, w_{2}\right)=(0,0,0) \quad$ if $\quad \frac{2(1-p)}{p} k<\Delta$.

The intuition for this lemma is quite simple. For a small $\Delta$ it is better to pay an incentive pay to the supervisor, with rewards proportional to $\Delta$, rather than incurring the audit costs; then contract $\alpha$, a contract which uses carrot only, is optimal. For a high $\Delta$, on the contrary, the supervisor has a large incentive to embezzle funds and therefore auditing is the cheapest way to deter embezzlement; then contract $\gamma$, which uses stick only, is optimal. For intermediate values of $\Delta$, a mix of carrot and stick as described in contract $\beta$ is optimal: More precisely, the stick $q_{0}=1$ is optimal in order to prevent the supervisor from misrepresenting $n=2$ or $n=1$ as $n=0$ while the carrot $w_{2}-w_{1}=\Delta$ is optimal in order to prevent the supervisor from misrepresenting $n=2$ as $n=1$.

Let $C^{I}(\Delta)$ denote the minimal financing cost as a function of $\Delta$. Lemma 5 implies that

$$
C^{I}(\Delta)=\left\{\begin{array}{cc}
2 \rho+2 p \Delta & \text { if } \Delta \leq \frac{(1-p)^{2}}{p(2-p)} k \\
2 \rho+(1-p)^{2} k+p^{2} \Delta & \text { if } \frac{(1-p)^{2}}{p(2-p)} k<\Delta \leq \frac{2(1-p)}{p} k \\
2 \rho+\left(1-p^{2}\right) k & \text { if } \frac{2(1-p)}{p} k<\Delta
\end{array}\right.
$$

(BE) is written as $2 r_{F}+2 p \Delta=C^{I}(\Delta)$, or equivalently as $r_{F}=\frac{1}{2} C^{I}(\Delta)-p \Delta \equiv r_{F}(\Delta)$. Direct inspection of (8) reveals that there exists a (unique) value of $\Delta$, denoted by $\Delta_{I}^{\max }$, such that $r_{F}(\Delta) \geq 0$ if and only if $\Delta \in\left[0, \Delta_{I}^{\max }\right]$. The value of $\Delta_{I}^{\max }$ depends on the sign of $2 \rho-(1-p)(3-p) k,{ }^{23}$ and in the following we assume $2 \rho>(1-p)(3-p) k$ (the opposite case is considered in Remark 1 below); thus $\Delta_{I}^{\max }=\frac{2 \rho+\left(1-p^{2}\right) k}{2 p}$ and $\Delta_{I}^{\max }>\frac{2(1-p)}{p} k$.

The optimal $\Delta$ is found by solving

$$
\max _{\Delta \in\left[0, \Delta_{I}^{\max }\right]} 2 p Y_{S}-2 p\left[\frac{1}{2} C^{I}(\Delta)-p \Delta+\Delta\right]-2(1-p) \psi\left[\frac{1}{2} C^{I}(\Delta)-p \Delta\right] .
$$

Let $B(\Delta)$ denote the objective function in (9). It turns out that $B(\Delta)$ is decreasing when $\Delta$ belongs to the interval $\left[0, \frac{(1-p)^{2}}{p(2-p)} k\right]$, is increasing when $\Delta$ belongs to the interval $\left[\frac{2(1-p)}{p} k, \Delta_{I}^{\max }\right]$, and has a non-straightforward monotonicity (and is concave) when $\Delta$ belongs to the middle interval $\left(\frac{(1-p)^{2}}{p(2-p)} k, \frac{2(1-p)}{p} k\right]$ because increasing $\Delta$ in this interval increases the financing cost but also provides some insurance by reducing $r_{F}$. Because of

\footnotetext{
${ }^{23}$ Precisely, $\Delta_{I}^{\max }=\frac{2 \rho+(1-p)^{2} k}{p(1-p)}$ and $\frac{(1-p)^{2}}{p(2-p)} k<\Delta_{I}^{\max } \leq \frac{2(1-p)}{p} k$ if $2 \rho \leq(1-p)(3-p) k$, while $\Delta_{I}^{\max }=$ $\frac{2 \rho+\left(1-p^{2}\right) k}{2 p}$ and $\Delta_{I}^{\max }>\frac{2(1-p)}{p} k$ if $2 \rho>(1-p)(3-p) k$.
} 
these features, a closed-form solution cannot be obtained without further assumptions; thus we consider the case of linear $\psi$, that is $\psi(r)=\theta r$ with $\theta>1$. Since it turns out that $C^{I}$ is concave, when $\psi$ is linear we obtain that $B(\Delta)$ is convex and so the optimal $\Delta$ is either 0 or $\Delta_{\max }^{I}$. In other terms, the optimal lending contract is either state non-contingent (i.e., $\Delta=0$ ) or has the maximal $\Delta$, and thus $r_{F}=0, r_{S}=\Delta_{I}^{\max }$. We have:

Proposition 2 Consider individual lending. Assume A1, $2 \rho>(1-p)(3-p) k$ and $\psi(r)=\theta r$ with $\theta>1$.

(i) Then the optimal grand contract is the best one between the two following contracts:

a. A state non-contingent lending contract $\left\{r_{S}=r_{F}=\rho\right\}$ with $\left\{q_{0}=q_{1}=q_{2}=0\right.$, $\left.w_{0}=w_{1}=w_{2}=0\right\} \quad($ contract $\alpha)$;

b. A state-contingent lending contract $\left\{r_{S}=\frac{2 \rho+\left(1-p^{2}\right) k}{2 p}, r_{F}=0\right\}$ with $\left\{q_{0}=q_{1}=1\right.$, $\left.q_{2}=0, w_{0}=w_{1}=w_{2}=0\right\}$ (contract $\left.\gamma\right)$.

(ii) The state non-contingent contract is optimal if and only if $(1+p) k \geq 2[\psi(\rho)-\rho]$.

The result in Proposition 2 is consistent with Proposition 1 since it depends on a similar trade-off between insurance gain and audit cost. However, we notice that this result relies on the assumption that $\psi$ is linear, otherwise it may occur that under individual lending the optimal contract is such that $r_{S}>r_{F}>0$, a feature which does not appear in the contracts of Proposition $2 .^{24}$

Remark 1 When $(1-p)(3-p) k>2 \rho$ holds, we find $\Delta_{I}^{\max }=\frac{2 \rho+(1-p)^{2} k}{p(2-p)}$ and the optimal grand contract is either the state non-contingent one described in Proposition 2(i)a or a state-contingent one $\left\{r_{S}=\Delta_{I}^{\max }, r_{F}=0\right\}$ with $\left\{q_{0}=1, q_{1}=q_{2}=0, w_{0}=w_{1}=0, w_{2}=\right.$ $\Delta_{I}^{\max }$ (the supervisory contract is $\beta$ with $\Delta=\Delta_{I}^{\max }$ ). The state non-contingent contract is optimal if and only if $p \rho+(1-p)^{2} k \geq(1-p)(2-p)[\psi(\rho)-\rho]$.

It is interesting to observe that when $(1-p)(3-p) k>2 \rho$ holds, it is optimal to use a mix of audit and incentive pay when the optimal lending contract is state-contingent.

\footnotetext{
${ }^{24}$ For instance consider $\psi(r)=r+3 r^{2}$ with $p=\frac{1}{2}, k=1, \rho=\frac{2}{3}$. Then $\Delta_{I}^{\max }=\frac{25}{12}$ and we have

$$
C^{I}(\Delta)=\left\{\begin{array}{ccc}
\frac{4}{3}+\Delta & \text { if } \Delta \leq \frac{1}{3} \\
\frac{19}{12}+\frac{1}{4} \Delta & \text { if } \frac{1}{3} \leq \Delta \leq 2 \\
\frac{25}{12} & \text { if } 2 \leq \Delta
\end{array} \quad \text { and } \quad B(\Delta)=\left\{\begin{array}{cc}
Y_{S}-\frac{8}{3}-\Delta & \text { if } \Delta \leq \frac{1}{3} \\
Y_{S}-\frac{665}{192}+\frac{49}{32} \Delta-\frac{27}{64} \Delta^{2} & \text { if } \frac{1}{3} \leq \Delta \leq 2 \\
Y_{S}-\frac{1025}{192}+\frac{25}{8} \Delta-\frac{3}{4} \Delta^{2} & \text { if } 2 \leq \Delta \leq \frac{25}{12}
\end{array}\right.\right.
$$
}

In the interval $\left[\frac{1}{3}, 2\right], B(\Delta)$ is maximized at $\Delta=\frac{49}{27}$ with $B\left(\frac{49}{27}\right)=Y_{S}-\frac{56}{27}$. Furthermore, $B(0)=Y_{S}-\frac{8}{3}$ and $B\left(\frac{25}{12}\right)=Y_{S}-\frac{25}{12}$. Since $\frac{56}{27}<\frac{25}{12}$ and $\frac{56}{27}<\frac{8}{3}$, the optimal lending contract is $r_{F}=\frac{1}{2} C^{I}\left(\frac{49}{27}\right)-\frac{1}{2} \cdot \frac{49}{27}=\frac{3}{27}$, $r_{S}=r_{F}+\frac{49}{27}=\frac{52}{27}$, with supervisory contract $\beta:\left(q_{0}, q_{1}, q_{2}\right)=(1,0,0)$ and $\left(w_{0}, w_{1}, w_{2}\right)=\left(0,0, \frac{49}{27}\right)$. 


\section{Comparison: group versus individual lending}

The following table summarizes the total NPV when $\psi$ is linear and $2 \rho \geq(1-p)(3-$ $p) k$ under the optimal state non-contingent or state-contingent contract, depending on whether the lender uses group or individual lending.

\begin{tabular}{|c|c|c|}
\hline Lending & Optimal state non-contingent contract & Optimal state-contingent contract \\
\hline Group & $V-(1-p)^{2} 2(\psi(\rho)-\rho)$ & $V-(1-p)^{2} k$ \\
\hline Individual & $V-\left[(1-p)^{2}+p(1-p)\right] 2(\psi(\rho)-\rho)$ & $V-\left[(1-p)^{2}+2 p(1-p)\right] k$ \\
\hline
\end{tabular}

where $V \equiv 2 p Y_{S}-2 \rho$ represents the NPV when the supervisor is honest.

Conditional on that the lender uses the optimal state non-contingent contract, or the optimal state-contingent contract, the change from individual lending to group lending strictly increases the NPV. In the case of the optimal state non-contingent contract, group lending provides a partial insurance in that when only one project succeeds, the borrower whose project failed does not pay anything (i.e. $r_{F S}=0$ ) while there is no such insurance under individual lending. In the case of the optimal state-contingent contract, full insurance is provided by both types of lending. However, the audit cost is lower under group lending: by making the borrowers' aggregate repayment when both projects succeed equal to the one when only one succeeds, the lender needs to conduct audit only when both projects fail. By contrast, under individual lending, the lender should conduct audit whenever at least one project fails.

Summarizing, we have

Proposition 3 Assume A1, $2 \rho>(1-p)(3-p) k$ and $\psi(r)=\theta r$ with $\theta>1$.

(i) When the supervisor is honest, group lending does not increase the borrowers' payoff with respect to individual lending.

(ii) When the supervisor can misbehave, group lending strictly dominates individual lending since it either reduces the audit cost or provides borrowers with more insurance.

\section{Mutual insurance}

Up to now, we have not considered the possibility that the two borrowers can sign a sidecontract between themselves, while some related literature considers side-contracting. ${ }^{25}$ In our model, the borrowers might have an interest to sign a side-contract to provide

\footnotetext{
${ }^{25}$ See Laffont and N'Guessan (2000), Laffont (2003), Laffont and Rey (2003), and Rai and Sjöström (2004)
} 
mutual insurance. More precisely, consider the timing in which, after accepting the lending contract and before the realization of the state of nature, the borrowers sign a binding side-contract which specifies a state-contingent side-payment between themselves. Since the lending contract and the agents are symmetric, a side-contract does not need to specify any side-payment when both projects succeed or both fail. Hence, a side-contract only specifies a monetary transfer $x$ that a borrower whose project succeeds makes to a borrower whose project fails such that the latter uses $x$ to make his repayment to the lender. Note first that given a grand-contract, side-contracting has no impact on the supervisor's incentives since it does not affect the borrowers' aggregate payment schedule.

Consider first group lending. Then, we can show that the optimal grand-contract without side-contracting that we characterized in proposition 1 is still the optimal contract even though the borrowers can sign a side-contract. Indeed, the only instrument of the borrowers' coalition is $x$ but this instrument is useless since the optimal contract specifies $r_{F S}=0$.

Consider now individual lending. First, we note that the outcomes that the lender can achieve under individual lending are a subset of the outcomes achievable under group lending regardless of whether or not the borrowers can sign a side-contract. Therefore, the lender cannot obtain under individual lending an outcome superior to the best she can achieve under group lending. Second, if side-contracting is possible, the lender can achieve the outcome of the optimal state non-contingent group lending contract by offering the following individual lending contract $G^{I *}=\left\{r_{S}=r_{F}=\rho, w_{n}=0, q_{n}=0\right.$ for $\left.n=0,1,2\right\}$. Under $G^{I *}$, it is optimal for the borrowers to sign a side-contract specifying $x^{*}=\rho$ because it maximizes the borrowers' ex ante expected payoffs. Last, under individual lending, side-contracting does not allow the lender to achieve the outcome of the optimal state-contingent group lending contract in proposition $1(\mathrm{i}) \mathrm{b}$. The latter contract specifies a repayment schedule such that $2 r_{S S}=r_{S F}, r_{F S}=r_{F F}=0$. This kind of schedule cannot be obtained under individual lending because $r_{S S}=r_{S F}$ and $r_{F S}=r_{F F}$ must hold. As the table in section 5 reveals, the consequence is a higher audit cost under individual lending. Summarizing, we have:

Proposition 4 (i) Under group lending, the optimal grand-contract is the same regardless of whether or not the borrowers can sign a side-contract and the possibility of sidecontracting has no impact on their payoffs.

(ii) When the borrowers can sign a side-contract,

a. the borrowers' payoffs cannot be higher under individual lending than under group lending. 
b. If a state non-contingent contract is optimal under group lending, the maximal payoffs under group lending can be achieved also under individual lending by a grandcontact which induces the borrowers to sign a side-contract for mutual insurance.

c. If a state-contingent contract is optimal under group lending, the borrowers' payoffs are strictly higher under group lending than under individual lending.

Proposition 4(ii)b implies that, conditional on that a state non-contingent contract is optimal, our model does not necessarily predict that we should observe the use of group lending.

\section{Concluding remarks: transition from Grameen I to Grameen II}

Our paper studied the question of when it is optimal for a microfinance institution to use a state non-contingent repayment by focusing on the bank staff's incentive to embezzle borrowers' repayments. We found that if the optimal lending contract is state-contingent, in the case of group lending it is optimal to induce a staff member to behave well by using only audit even though a mix of audit and incentive pay can be used, whereas in the case of individual lending a mix of both instruments become optimal for moderately large audit cost. Therefore, a state non-contingent schedule is optimal if the cost of monitoring the staff's behavior is larger than the borrowers' gain from full insurance. When the optimal lending contract is state non-contingent, group lending is preferred to individual lending because the former provides borrowers with partial insurance. However, under individual lending, the borrowers themselves have an incentive to mutually provide such an insurance; then, individual lending is as good as group lending. When the optimal lending contract is state-contingent, we showed that group lending is strictly preferred to individual lending because the former allows to save audit cost.

Actually, the lending contract under Grameen I, the classic Grameen bank, specified a state non-contingent individual loan with joint liability ${ }^{26}$ but the bank discontinued the

\footnotetext{
${ }^{26}$ More generally, an individual lending contract with joint liability can be defined as the lending contract in which the repayment schedule of each borrower of a group depends only on the return realization of his own project but each borrower is responsible for the repayment of the other borrowers in the group in case of default. Hence, joint liability can trigger a repayment game among the borrowers as in Besley-Coate (1995). Our group lending contract is more general than the individual lending contract with joint liability since the former includes the latter as a subset and in addition the former can specify a repayment schedule that depends on the return realization of all group members' projects.
} 
practice of joint liability after its transition to Grameen II. More precisely, Dowla and Barua (2006) describe the transition, which was triggered by the flood of 1998, the worst in the history of Bangladesh, that made many borrowers unable to make repayments. This transition is characterized by the switch from the rigid repayment schedule to flexible ones that allow for rescheduling, the switch from joint liability to no joint liability, and new emphasis on voluntary saving in individual account.

The Grameen bank was forced to allow for rescheduling after the flood, otherwise there would have been massive defaults. However, Grameen II does not distinguish common shocks such as the flood from individual shocks such as disease and shocks on project return. Common shocks are observable to a third party including the lender and hence providing insurance against common shocks does not involve any agency cost and is desirable. For instance, rescheduling loan payments in a region severely affected by the flood is optimal. On the contrary, providing insurance against individual shocks which are observable only to the borrowers and the staff member in charge of them, which is the focus of our paper, can generate agency costs. Our paper suggests that the gain from providing such an insurance should be carefully weighed against the cost of controlling staff's discretion.

Furthermore, even under Grameen II, most disbursement is made through "the basic loan" specifying a rigid repayment schedule ${ }^{27}$. Our paper shows that in this case, joint liability is not necessary since borrowers have an incentive to provide mutual insurance. In addition, abandoning joint liability seems to be caused by the Grameen bank's transformation as a saving (and lending) institution as well as its decision to introduce flexibility to reschedule repayments. For instance, when members of a group have different saving levels, the burden of joint liability becomes asymmetric and hence creates a tension, which in turn reduces incentives to save.

\section{References}

Armendáriz de Aghion, B. 1999, "On the Design of a Credit Agreement with Peer Monitoring", Journal of Development Economics, 60:79-104

Armendáriz de Aghion, B. and C. Gollier. 2000, "Peer Group Formation in an Adverse Selection Model", Economic Journal, 110:632-643

\footnotetext{
${ }^{27}$ According to the monthly report of February 20, 2010, among the outstanding loans, the disbursement made through the basic loan is 756 million USD while the one made through the flexible one is 27 million USD. See http://www.grameeninfo.org/index.php?option $=$ com_content\&task=view\&id=453\&Itemid $=527$ accessed $\quad$ on March 4 , 2010.
} 
Armendáriz de Aghion, B. and J. Morduch. 2005, The Economics of Microfinance, MIT.

Aubert, Cécile, Alain de Janvry and Elisabeth Sadoulet. 2005, "Incentives with Non-Profit Objectives: Microfiancne Agents and the Selection of Very Poor Borrowers", Mimeo, Université Paris Dauphine and University of California at Berkeley.

Bazoberry, Eduardo. 2001, "We Aren't Selling Vacuum Cleaners: PRODEM's Experiences with Staff Incentives", Microbanking Bulletin, April:11-13.

Besley, T. and S. Coate. 1995, "Group Lending, Repayment, Incentives and Social Collateral", Journal of Development Economics, 46:1-18

Bond, P. and A. Rai. 2002, "Collateral Substitutes in Microfinance", Manuscript.

Bornstein, David. 1996, The Price of a Dream, University of Chicago, Chicago.

Che, Yeon-Koo. 2002, "Joint Liability and Peer Monitoring under Group Lending," Contributions to Theoretical Economics, 2, Article 3.

Conning, Jonathan. 1999, "Outreach, sustainability and leverage in monitored and peer-monitored lending", Journal of Development Economics, 60:51-77

Diamond, D. 1984, "Financial Intermediation and Delegated Monitoring," Review of Economic Studies, 51: 393-414.

Dowla, Asif and Dipal Barua. 2006. The Poor Always Pays Back: The Grameen II Story. Kumarian Press, Inc.

Fantaye, Dawit Kiros. 2004, "Fighting Corruption and Embezzlement in Third World Countries", Journal of Criminal Law, 68(2): 170-176.

Faure-Grimaud, Antoine, Jean-Jacques Laffont and David Martimort, 2003, "Collusion, Delegation and Supervision with Soft Information", Review of Economic Studies, 70:253-280.

Gale, D. and M. Hellwig, 1985, "Incentive-Compatible Debt Contracts: The OnePeriod Problem," Review of Economic Studies, 52: 647-663.

Ghatak, M. 1999, "Group Lending, Local Information and Peer Selection", Journal of Development Economics, 60:27-50

Ghatak, M. and T. W. Guinnane, 1999, "The Economics of Lending with Joint Liability: Theory and Practice", Journal of Development Economics, 195-228

Jain, Sanjay and Ghazala Mansuri. 2003, "A Little at a time: The Use of Regularly Scheduled Repayments in Microfinance Programs", Journal of Development Economics, $72: 253-279$

Jeon, Doh-Shin and Domenico Menicucci. 2009, "When Is the Optimal Lending Contract in Microfinance State Non-Contingent?", Working paper, Universitat Pompeu Fabra. 
Kofman, F. and Lawarrée, J. 1993, "Collusion in Hierarchical Agency" Econometrica, 61:629-656

Laffont, J.-J. 2003, "Collusion and Group Lending with Adverse Selection", Journal of Development Economics, 70: 329-348

Laffont, J.-J and D. Martimort. 2002. The Theory of Incentives: the Principal-Agent Model. Princeton University Press.

Laffont, J.-J and T. N'Guessan. 2000, "Group Lending with Adverse Selection", European Economic Review 44:773-784

Laffont, J.-J. and P. Rey, 2003, "Moral Hazard, Collusion and Group Lending", Mimeo, University of Toulouse

Laffont, J.-J. and J. Tirole. 1991, "The Politics of Government Decision Making: A Theory of Regulatory Capture", Quarterly Journal of Economics, 70: 329-348

Mknelly Barbara and Michael Kevane, 2000, "Improving Design and Performance of Group Lending: Suggestion from Burkina Faso", World Development 1060:1089-1127.

Morduch, Jonathan 1999, "The Microfinance Promise", Journal of Economic Literature, 37:1569-1614

Rai, A. and T. Sjöström. 2004, "Is Grameen Lending Efficient? Repayment Incentives and Insurance in Village Economies", Review of Economic Studies, 71:217-234.

Sadoulet, L., 2000, The Role of Mutual Insurance in Group Lending, Mimeo, ECARES.

Stiglitz, J. 1990, "Peer Monitoring and Credit Markets", World Bank Economic Review, 4(3): 351-366

Tirole, Jean, 1986, "Hierarchies and Bureaucracies: On the Role of Collusion in Organizations", Journal of Law, Economics and Organization, 2:181-214

Townsend, R. 1979, "Optimal Contracts and Competitive Markets with Costly State Verification," Journal of Economic Theory 21: 417-425

Townsend, R and J. Yaron. 2001, "The Credit Risk-Contingency System of An Asian Development Bank," Economic Perspectives Q3: 31-48

Varian, H. 1990, "Monitoring Agents With Other Agents", Journal of Institutional and Theoretical Economics 146: 175-176

Yunus, Muhammad, 1998, Banker to the Poor, University Press Limited.

\section{Appendix}

\section{Proof of Lemma 1}

Let $R(1)$ be given, which means that $r_{S F}+r_{F S}$ is given. We prove that if $Y_{S} \geq R(1)$, then it is optimal to set $r_{F S}=0$ and thus $r_{S F}=R(1)$. Since $R(1)$ is given, $\left(r_{S F}, r_{F S}\right)$ 
does not affect (3) nor (BE) but affects the borrowers' payoff only through the term

$$
2 p(1-p)\left[Y_{S}-r_{S F}-\psi\left(r_{F S}\right)\right]=2 p(1-p)\left[Y_{S}-R(1)+r_{F S}-\psi\left(r_{F S}\right)\right]
$$

in which the equality comes from $r_{S F}=R(1)-r_{F S}$. In writing (10), we implicitly assumed that $r_{S F} \leq Y_{S}$. As long as this condition holds, maximizing (10) with respect to $r_{F S}$ tells us that any $r_{F S}>0$ is dominated by $r_{F S}=0$ since $\psi^{\prime}(r)>1$ for any $r>0$. We prove in Proposition 1 that the inequality $r_{S F} \leq Y_{S}$ is satisfied in the optimal lending contract given that A1(ii) holds. ${ }^{28}$

\section{Proof of Lemma 2}

Step 1 If $G$ is such that (BE) is slack, then it is possible to increase the objective function; thus the solution to the relaxed problem $\left(L r^{G}\right)$ is such that (BE) binds. Moreover, $w_{0}=0$ and $q_{2}=0$.

Proof If (BE) does not bind in the solution to $\left(L r^{G}\right)$, then we can find an alternative grand contract with reduced borrowers' payments, unchanged wages, and unchanged audit probabilities, which yields a higher value for the objective function. Precisely, in each of the following cases we reduce the borrowers' payments in a way that (i) satisfies (4) [given that (4) was satisfied initially]; (ii) leaves the right hand side of (BE) unchanged and reduces slightly the left hand side of $(\mathrm{BE})$, thus leaving $(\mathrm{BE})$ satisfied as $(\mathrm{BE})$ was slack initially; (iii) increases the borrowers' payoff since their payments are lower.

In case that $r_{F F}>0$, consider $\Delta r_{F F}=-\varepsilon, \Delta r_{S S}=-\varepsilon$ and either $\Delta r_{S F}=-2 \varepsilon$ or $\Delta r_{F S}=-2 \varepsilon$ (at least one between $r_{S F}$ and $r_{F S}$ is positive), for $\varepsilon>0$ and small: In this way (4) is unaffected. In case that $r_{F F}=0$, we examine two sub-cases. If $r_{S F}+r_{F S}>0$, consider $\Delta r_{S F}=-2 \varepsilon$ or $\Delta r_{F S}=-2 \varepsilon$ (at least one between $r_{S F}$ and $r_{F S}$ is positive) and $\Delta r_{F F}=0, \Delta r_{S S}=-\varepsilon$ : In this way $\Delta_{2}$ is unchanged and $\Delta_{1}$ is reduced, thus relaxing (4). In case that $r_{F F}=0$ and $r_{S F}+r_{F S}=0$, then consider $\Delta r_{S F}=\Delta r_{F S}=\Delta r_{F F}=0$ and $\Delta r_{S S}=-\varepsilon$ : In this way $\Delta_{2}$ is reduced and $\Delta_{1}$ is unchanged, thus weakly relaxing (4). $\operatorname{In}\left(L r^{G}\right)$, (a) $q_{2}$ appears only in the right hand side of $(\mathrm{BE})$ and $q_{2}=0$ relaxes (BE) most; (b) $w_{0}$ appears only in the right hand side of (BE) and in (4), and $w_{0}=0$ relaxes these constraints most.

Step 2 The solution to $\left(L r^{G}\right)$ is such that both $\left(\mathrm{IC}_{21}\right)$ and $\left(\mathrm{IC}_{10}\right)$ bind.

\footnotetext{
${ }^{28}$ Furthermore, if we allow for $r_{F S}<0$ then (10) becomes $2 p(1-p)\left[Y_{S}-R(1)\right]$ and does not depend on $r_{F S}$. However, since $r_{S F}=R(1)-r_{F S}$, a negative $r_{F S}$ makes $r_{S F}$ larger than $R(1)$ and it is more difficult to satisfy $r_{S F} \leq Y_{S}$.
} 
Proof Constraint $\left(\mathrm{IC}_{10}\right)$ binds since (a) the right hand side of $\left(\mathrm{IC}_{10}\right)$ is non negative and satisfying $\left(\mathrm{IC}_{10}\right)$ implies that $w_{1} \geq 0$ holds; (b) reducing $w_{1}$ reduces the financing cost and relaxes $\left(\mathrm{IC}_{21}\right)$.

Regarding $\left(\mathrm{IC}_{21}\right)$, notice that if $\left(\mathrm{IC}_{21}\right)$ is slack then $q_{1}=0$, because when $q_{1}>0$ it is profitable and feasible to reduce $q_{1}$ in order to relax (BE) and increase the objective function. Thus $w_{2}>\Delta_{2}+w_{1}$ needs to hold and there are two cases to consider: when $\left(\mathrm{IC}_{20}\right)$ binds and when $\left(\mathrm{IC}_{20}\right)$ is slack. If $\left(\mathrm{IC}_{20}\right)$ binds, then we have $w_{2}=\left(1-q_{0}\right) \Delta_{2}+$ $\left(1-q_{0}\right) \Delta_{1}$ and hence $w_{2}>\Delta_{2}+w_{1}$ fails to hold because $w_{1}=\left(1-q_{0}\right) \Delta_{1}$. If $\left(\mathrm{IC}_{20}\right)$ is slack, then it is profitable and feasible to reduce $w_{2}$ in order to relax (BE) and increase the objective function, contradicting optimality.

Step 3 The solution to $\left(L r^{G}\right)$ is such that $\Delta_{2}=0, q_{1}=0$ and $w_{2}=\left(1-q_{0}\right) \Delta_{1}$.

Proof Suppose that $G$ is a solution to $\left(L r^{G}\right)$, so that the results in Steps 1 and 2 hold, and moreover assume that $\Delta_{2}>0$. We show that there exists $G^{\prime}$ which is strictly better than $G$ and satisfies $\Delta_{2}^{\prime}<\Delta_{2}$. In this way we prove that whenever a lending contract is such that $\Delta_{2}>0$, we can find another contract $G^{\prime}$ with $\Delta_{2}^{\prime}<\Delta_{2}$ which is strictly better than $G$. Ultimately, this implies that the optimal contract is such that $\Delta_{2}=0$. We need to distinguish the case in which $\left(\mathrm{IC}_{20}\right)$ is slack from the case in which $\left(\mathrm{IC}_{20}\right)$ binds.

If $\left(\mathrm{IC}_{20}\right)$ is slack, then we pick $G^{\prime}$ such that $r_{F S}^{\prime}=r_{F S}, r_{S F}^{\prime}=r_{S F}+\frac{p}{2-p} \varepsilon, r_{S S}^{\prime}=r_{S S}-\frac{1-p}{2-p} \varepsilon$, $r_{F F}^{\prime}=r_{F F}$ for a small $\varepsilon>0$, thus $\Delta_{2}^{\prime}=\Delta_{2}-\varepsilon, \Delta_{1}^{\prime}=\Delta_{1}+\frac{p}{2-p} \varepsilon$ and $\Delta_{2}^{\prime}+\Delta_{1}^{\prime}=\Delta_{2}+\Delta_{1}-$ $\frac{2(1-p)}{2-p} \varepsilon$. Moreover, we set $w_{1}^{\prime}=w_{1}+\left(1-q_{0}\right) \frac{p}{2-p} \varepsilon, w_{2}^{\prime}=w_{2}+\left(1-q_{1}\right)\left[-\varepsilon+\left(1-q_{0}\right) \frac{p}{2-p} \varepsilon\right]$ and $q_{n}^{\prime}=q_{n}$ for $n=0,1,2$. It is simple to see that the objective function has the same value in $G^{\prime}$ as in $G$ since a borrower's payment is unchanged when his project fails, and is unchanged in expectation when his project is successful. Next we verify that $G^{\prime}$ satisfies (4) and that (BE) is slack in $G^{\prime}$. Then Step 1 implies that the objective function can be increased by reducing suitably the borrowers' payments.

In order to see that $G^{\prime}$ satisfies $(4)$, we notice that $\left(\mathrm{IC}_{21}\right)$ and $\left(\mathrm{IC}_{10}\right)$ are satisfied in $G^{\prime}$ given that they were satisfied in $G ;\left(\mathrm{IC}_{20}\right)$ holds in $G^{\prime}$ as it was slack in $G$ and $\varepsilon>0$ is small. Regarding (BE), the left hand side is unchanged since the borrowers' expected payment is the same as in $G$. On the other hand, the change in the expected wage paid to the supervisor is

$$
2 p(1-p)\left(1-q_{0}\right) \frac{p}{2-p} \varepsilon+p^{2}\left(1-q_{1}\right)\left[-\varepsilon+\left(1-q_{0}\right) \frac{p}{2-p} \varepsilon\right]
$$

and now we prove that (11) is negative. First notice that from $\left(\mathrm{IC}_{21}\right)$ binding and $\left(\mathrm{IC}_{20}\right)$ slack it follows that $\left(1-q_{1}\right)\left[\Delta_{2}+\left(1-q_{0}\right) \Delta_{1}\right]>\left(1-q_{0}\right)\left(\Delta_{2}+\Delta_{1}\right)$ and thus $1-q_{1}>1-q_{0}$. Since $-\varepsilon+\left(1-q_{0}\right) \frac{p}{2-p} \varepsilon<0$, we infer that (11) is smaller than $2 p(1-p)\left(1-q_{0}\right) \frac{p}{2-p} \varepsilon+$ 
$p^{2}\left(1-q_{0}\right)\left[-\varepsilon+\left(1-q_{0}\right) \frac{p}{2-p} \varepsilon\right]=-\frac{p^{3}\left(1-q_{0}\right) q_{0}}{2-p} \varepsilon \leq 0$; therefore (BE) is slack in $G^{\prime}$.

If $\left(\mathrm{IC}_{20}\right)$ binds, then using $\left(\mathrm{IC}_{21}\right)$ we find

$$
\left(1-q_{1}\right)\left[\Delta_{2}+\left(1-q_{0}\right) \Delta_{1}\right]=\left(1-q_{0}\right)\left(\Delta_{2}+\Delta_{1}\right)
$$

Suppose that $q_{1}=0$. Then (12) reduces to $\Delta_{2}+\left(1-q_{0}\right) \Delta_{1}=\left(1-q_{0}\right)\left(\Delta_{2}+\Delta_{1}\right)$ and thus $q_{0}=0$. Therefore $w_{1}=\Delta_{1}, w_{2}=\Delta_{1}+\Delta_{2}$ and since $r_{S F}=2 r_{F F}+\Delta_{1}$ and $2 r_{S S}=r_{S F}+\Delta_{2}$, it turns out that $(\mathrm{BE})$ reduces to $r_{F F}=\rho$. Then consider $G^{\prime}$ such that $r_{F F}^{\prime}=\rho, r_{F S}^{\prime}=0$, $r_{S F}=2 \rho, r_{S S}=\rho$ (thus $\Delta_{2}^{\prime}=\Delta_{1}^{\prime}=0$ ) and $w_{n}^{\prime}=0, q_{n}^{\prime}=0$ for $n=0,1,2$. In this way (4) is satisfied, (BE) holds with equality and each borrower's payment is the same as in $G$ when his project fails, but is smaller in expectation when his project is successful; thus the objective function increases.

Now we consider the case in which $q_{1} \in(0,1]$ and from (12) we find $1-q_{1} \geq 1-q_{0}$, which is equivalent to $q_{0} \geq q_{1}$. Consider $G^{\prime}$ such that $r_{F F}^{\prime}=r_{F F}, r_{F S}^{\prime}=r_{F S}, r_{S F}^{\prime}=r_{S F}+\frac{p}{2-p} \Delta_{2}$, and $r_{S S}^{\prime}=r_{S S}-\frac{1-p}{2-p} \Delta_{2}$; thus $\Delta_{1}^{\prime}=\Delta_{1}+\frac{p}{2-p} \Delta_{2}, \Delta_{2}^{\prime}=0, \Delta_{1}^{\prime}+\Delta_{2}^{\prime}=\Delta_{1}+\frac{p}{2-p} \Delta_{2}$. Moreover, we set $w_{1}^{\prime}=w_{1}+\left(1-q_{0}\right) \frac{p}{2-p} \Delta_{2}, w_{2}^{\prime}=w_{2}-\left(1-q_{0}\right) \frac{2-2 p}{2-p} \Delta_{2}$ and $q_{2}^{\prime}=0, q_{1}^{\prime}=q_{1}-\varepsilon$ with $\varepsilon>0$ and small, $q_{0}^{\prime}=q_{0}$. In $G^{\prime}$, the borrowers' payoff is the same as in $G$ since the payment of each borrower is unaltered when his project fails, and his payment in case of success is unchanged in expectation. Next we verify that $G^{\prime}$ satisfies (4) and that (BE) is slack in $G^{\prime}$. Then Step 1 implies that the objective function can be increased by reducing suitably the borrowers' payments.

We start by noticing that (4) is satisfied. This is immediate for $\left(\mathrm{IC}_{10}\right)$ and $\left(\mathrm{IC}_{20}\right)$, while $\left(\mathrm{IC}_{21}\right)$ reduces to

$$
w_{2}-\left(1-q_{0}\right) \frac{2-2 p}{2-p} \Delta_{2} \geq\left(1-q_{1}+\varepsilon\right)\left[w_{1}+\left(1-q_{0}\right) \frac{p}{2-p} \Delta_{2}\right]
$$

Since $\left(\mathrm{IC}_{21}\right)$ binds in $G$, we have that $w_{2}=\left(1-q_{1}\right)\left(\Delta_{2}+w_{1}\right)$ and thus (13) boils down to

$$
\left[\left(2-p-q_{1} p\right) q_{0}-2(1-p) q_{1}\right] \Delta_{2} \geq \varepsilon\left[(2-p) w_{1}+\left(1-q_{0}\right) p \Delta_{2}\right]
$$

In order to see that $(14)$ is satisfied, notice that if $q_{1} \in(0,1)$ then $q_{0} \geq q_{1}$ implies $\left(2-p-q_{1} p\right) q_{0}-2(1-p) q_{1} \geq\left(2-p-q_{1} p\right) q_{1}-2(1-p) q_{1}=q_{1}\left(1-q_{1}\right) p>0$, and thus (14) holds since $\varepsilon>0$ is close to zero. If instead $q_{1}=1$, then $q_{0}=1$ by (12) and $w_{1}=0$ given that $\left(\mathrm{IC}_{10}\right)$ binds in $G$; then (14) is satisfied again.

Regarding (BE), we see that (i) the borrowers' expected payment is the same as in $G$; (ii) the expected wage bill is the same as in $G$; (iii) the cost of auditing is reduced as $q_{1}^{\prime}<q_{1}$. Finally, after finding that $\Delta_{2}=0$, from $\left(\mathrm{IC}_{20}\right)$ we obtain $\left(1-q_{1}\right)\left(1-q_{0}\right) \Delta_{1} \geq\left(1-q_{0}\right) \Delta_{1}$. If $\left(1-q_{0}\right) \Delta_{1}>0$, then we obtain $q_{1}=0$; if $\left(1-q_{0}\right) \Delta_{1}=0$, then $q_{1}$ could be any number in $[0,1]$, but $q_{1}=0$ is optimal to minimize the financing cost. In either case, $w_{2}=\left(1-q_{0}\right) \Delta_{1}$. 


\section{Proof of Proposition 1}

The proof of Proposition 1(i) appears in the text. Proposition 1(ii) follows by comparing the borrowers' payoffs in the two contracts described in Proposition 1(i).

It is simple to verify that the neglected upward incentive constraints $\left(\mathrm{IC}_{12}\right),\left(\mathrm{IC}_{02}\right),\left(\mathrm{IC}_{01}\right)$ are satisfied by the two contracts in Proposition 1(i).

Furthermore, we verify that $Y_{S}$ is large enough, given A1, to make the borrowers' payoff positive in the optimal grand contract and to satisfy Lemma 1. First consider the state non-contingent contract described in (i)a. The borrowers' payoff with this contract is $2 p Y_{S}-2 \rho-2(1-p)^{2}[\psi(\rho)-\rho]$ and A1(i) implies that this payoff is positive. ${ }^{29}$ Furthermore, the condition $r_{S F} \leq Y_{S}$ is satisfied since $r_{S F}=2 \rho<\Delta_{1}^{\max }$ and A1(ii) requires $Y_{S} \geq$ $\Delta_{1}^{\max }$. Regarding the state-contingent contract described in (i)b, the borrowers' payoff is $2 p Y_{S}-p(2-p) \Delta_{1}^{\max }=2 p Y_{S}-2 \rho-(1-p)^{2} k$ which is positive by A1(i). Finally, $r_{S F}=\Delta_{1}^{\max }$ and thus $r_{S F} \leq Y_{S}$ is satisfied because of A1(ii).

\section{Proof of Lemma 3}

We start with a preliminary result which helps prove Lemma 3.

Lemma 6 Consider a lending contract $\left\{r_{S S}, r_{S F}, r_{F S}, r_{F F}\right\}$ such that $r_{F S}=0$ and $r_{F F}>$ 0. Next, consider a lending contract $\left\{r_{S S}^{\prime}, r_{S F}^{\prime}, r_{F S}^{\prime}, r_{F F}^{\prime}\right\}$ such that $r_{F S}^{\prime}=0, r_{F F}^{\prime}<r_{F F}$ and such that the borrowers' expected payment is the same in the two contracts. Then the borrowers' payoff is larger with the second contract

Proof. Let $C \equiv p^{2} 2 r_{S S}+2 p(1-p) r_{S F}+(1-p)^{2} 2 r_{F F}=p^{2} 2 r_{S S}^{\prime}+2 p(1-p) r_{S F}^{\prime}+(1-p)^{2} 2 r_{F F}^{\prime}$ denote the borrowers' expected payment under either contract. The borrowers' payoff with $\left\{r_{S S}, r_{S F}, r_{F S}, r_{F F}\right\}$ is $2 p Y_{S}-C+(1-p)^{2} 2 r_{F F}-(1-p)^{2} 2 \psi\left(r_{F F}\right)$, and is decreasing in $r_{F F}^{\prime}$ since $\psi^{\prime}(r)>1$ for any $r>0$. Given that $r_{F F}^{\prime}<r_{F F}$, it follows that borrowers prefer $\left\{r_{S S}^{\prime}, r_{S F}^{\prime}, r_{F S}^{\prime}, r_{F F}^{\prime}\right\}$ to $\left\{r_{S S}, r_{S F}, r_{F S}, r_{F F}\right\}$.

Now we prove Lemma 3 by considering all the possible cases in which $\Delta_{1}<0$ and/or $\Delta_{2}<0$ : In any such case we prove that it is possible to increase (weakly) the borrowers' payoff by satisfying $\Delta_{1} \geq 0$ and $\Delta_{2} \geq 0$. In particular, we need to consider four different regimes.

1. $R(0) \geq \max \{R(1), R(2)\}$ : regime $\mathrm{B}$.

\footnotetext{
${ }^{29}$ Notice that A1 is more restrictive than needed for the case of group lending because we want the same assumption to cover the case of individual lending as well.
} 
Let $G^{B}$ denote the best grand contract within the set of grand contracts satisfying $R(0) \geq$ $R(1)$ and $R(0) \geq R(2)$. We show that $G^{B}=G^{\prime}$, with $R^{\prime}(0)=R^{\prime}(1)=R^{\prime}(2)=2 \rho$ and $w_{0}^{\prime}=w_{1}^{\prime}=w_{2}^{\prime}=0, q_{0}^{\prime}=q_{1}^{\prime}=q_{2}^{\prime}=0$; thus, $G^{B}$ satisfies $\Delta_{1} \geq 0$ and $\Delta_{2} \geq 0$. It is easy to see that $G^{\prime}$ is feasible because it satisfies (3) and (BE). The borrowers' payoff in $G^{\prime}$ is $2 p Y_{S}-p^{2} R^{\prime}(2)-2 p(1-p) R^{\prime}(1)-(1-p)^{2} 2 \psi\left(\frac{R^{\prime}(0)}{2}\right)$ because A1(ii) implies that $Y_{S}>R^{\prime}(1)=2 \rho$ and thus Lemma 1 applies. The borrowers' payoff with a grand contract $G$ such that $R(0)>\max \{R(1), R(2)\}$ or $R(0)=\max \{R(1), R(2)\}>\min \{R(1), R(2)\}$ is smaller than payoff with $G^{\prime}$ because of the following arguments. First, suppose for the moment that the borrowers' expected payment is the same in $G$ as in $G^{\prime}$. Then $G^{\prime}$ is better than $G$ because of Lemma 6 , given that $R^{\prime}(0)=R^{\prime}(1)=R^{\prime}(2)$ implies $R(0)>R^{\prime}(0)$. Second, the expected payment in $G$ is actually larger than in $G^{\prime}$ because $R(0)=R(1)=R(2)$ fails to hold and therefore the financing cost is larger than $2 \rho$ since some cost must be borne to discourage embezzlement. Third, while $Y_{S} \geq R^{\prime}(1)$ holds, it may be that $Y_{S}<R(1)$ and in this case borrowers face some cost from reducing consumption in states $S F$ and $F S$ and not only in state $F F$.

2. $R(2) \geq R(0) \geq R(1)$ : regime $C$.

We show that within the set of grand contracts satisfying $R(2) \geq R(0) \geq R(1)$, the best contract $G^{C}$ is such that $R^{C}(0)=R^{C}(1)$ and therefore $\Delta_{1} \geq 0$ and $\Delta_{2} \geq 0$ are satisfied. Let $\Delta_{20} \equiv R(2)-R(0) \geq 0$ and $\Delta_{01} \equiv R(0)-R(1) \geq 0$. We study the following relaxed program in which we consider only $\left(\mathrm{IC}_{21}\right),\left(\mathrm{IC}_{20}\right)$ and $\left(\mathrm{IC}_{01}\right)$ among the incentive constraints:

$$
\left\{\begin{array}{c}
\left(\mathrm{IC}_{21}\right) \quad w_{2} \geq\left(1-q_{1}\right)\left(\Delta_{20}+\Delta_{01}+w_{1}\right) \\
\left(\mathrm{IC}_{20}\right) \quad w_{2} \geq\left(1-q_{0}\right)\left(\Delta_{20}+w_{0}\right) \\
\left(\mathrm{IC}_{01}\right) \quad w_{0} \geq\left(1-q_{1}\right)\left(\Delta_{01}+w_{1}\right)
\end{array}\right.
$$

We prove that $G^{C}$ is such that $\Delta_{01}^{C}=0$ by showing that starting from any feasible contract $G$ satisfying $\Delta_{01}>0$, we can find $G^{\prime}$ which is strictly better than $G$ and such that $\Delta_{01}^{\prime}=0$. Precisely, let $w_{n}^{\prime}=w_{n}, q_{n}^{\prime}=q_{n}$ for $n=0,1,2$ and $R^{\prime}(1)=R(1)+\left[p^{2}+(1-p)^{2}\right] \Delta_{01}$, $R^{\prime}(2)=R(2)-2 p(1-p) \Delta_{01}, R^{\prime}(0)=R(0)-2 p(1-p) \Delta_{01}$; then $\Delta_{01}^{\prime}=0<\Delta_{01}$ and $\Delta_{20}^{\prime}=\Delta_{20}$. As a consequence, the incentive constraints in (15) are weakly relaxed and the borrowers' expected payment is unchanged; thus $G^{\prime}$ satisfies (BE) and (15), given that $G$ is feasible. Furthermore, $R^{\prime}(1)>R(1)$ and $R^{\prime}(0)<R(0)$ and thus Lemmas 1 and 6 imply that the borrowers' payoff is higher in $G^{\prime}$ than in $G$ as long as $Y_{S} \geq R^{\prime}(1)$. This proves that $G^{C}$ is such that $\Delta_{01}^{C}=0$ as long as $R^{C}(1) \leq Y_{S}$. Now we characterize a few properties of $G^{C}$ under the assumption that $Y_{S}$ is large enough and then verify that $Y_{S} \geq R^{C}(1)$ given A1(ii). When $\Delta_{01}=0$ and $\Delta_{20} \geq 0$ it is optimal to set (i) $q_{2}=0, w_{1}=0$ (we can 
argue like in the proof of Step 1 in the proof of Lemma 2), $w_{0}=0$ because the right hand side of $\left(\mathrm{IC}_{01}\right)$ is 0 ; (ii) $q_{1}=q_{0}=q$ because if $q_{1}>q_{0}$ (for instance), then $\left(\mathrm{IC}_{20}\right)$ binds, $\left(\mathrm{IC}_{21}\right)$ is slack and it is profitable to reduce $q_{1}$ slightly in other to reduce the audit cost $k q_{1}$ without affecting $w_{2}$. Then $\left(\mathrm{IC}_{21}\right)$ is equivalent to $\left(\mathrm{IC}_{20}\right)$ and $w_{2}=(1-q) \Delta_{20}$. From (BE) binding we find $R(1)+p^{2} \Delta_{20}=2 \rho+p^{2}(1-q) \Delta_{20}+\left(1-p^{2}\right) k q$. The right hand side, that is the financing cost, is linear in $q$ and thus is minimized with respect to $q$ at $q=0$ or at $q=1$. In either case we find $R(1) \leq 2 \rho$ and A1(ii) implies that $2 \rho$ is smaller than $Y_{S}$. Finally, given $w_{2}=(1-q) \Delta_{20}$, the incentive constraints neglected in (15) are satisfied and we have proved that $G^{C}$ satisfies $\Delta_{01}=0$.

3. $R(1) \geq R(2) \geq R(0)$ : regime $D$.

We show that within the set of grand contracts satisfying $R(1) \geq R(2) \geq R(0)$, the best contract $G^{D}$ is such that $R^{D}(1)=R^{D}(2)$, and therefore it satisfies $\Delta_{1} \geq 0$ and $\Delta_{2} \geq 0$. Let $\Delta_{12} \equiv R(1)-R(2) \geq 0$ and $\Delta_{20} \equiv R(2)-R(0) \geq 0$. We study a relaxed program in which we consider only $\left(\mathrm{IC}_{12}\right),\left(\mathrm{IC}_{10}\right)$ and $\left(\mathrm{IC}_{20}\right)$ among the incentive constraints:

$$
\left\{\begin{array}{c}
\left(\mathrm{IC}_{12}\right) \quad w_{1} \geq\left(1-q_{2}\right)\left(\Delta_{12}+w_{2}\right) \\
\left(\mathrm{IC}_{10}\right) \quad w_{1} \geq\left(1-q_{0}\right)\left(\Delta_{12}+\Delta_{20}+w_{0}\right) \\
\left(\mathrm{IC}_{20}\right) \quad w_{2} \geq\left(1-q_{0}\right)\left(\Delta_{20}+w_{0}\right)
\end{array}\right.
$$

By arguing as in Steps 1-2 in the proof of Lemma 2 we find that in any solution to the relaxed problem $w_{0}=0, q_{1}=0,\left(\mathrm{IC}_{20}\right)$ and $\left(\mathrm{IC}_{12}\right)$ bind; thus $w_{2}=\left(1-q_{0}\right) \Delta_{20}$ and $w_{1}=\left(1-q_{2}\right)\left[\Delta_{12}+\left(1-q_{0}\right) \Delta_{20}\right]$. Now suppose that $G$ is a solution to the relaxed problem and such that $\Delta_{12}>0$. We find $G^{\prime}$ which is weakly better than $G$ and satisfies $\Delta_{12}^{\prime}<\Delta_{12}$. Let $R^{\prime}(2)=R(2)+\frac{2(1-p)}{2-p} \varepsilon, R^{\prime}(1)=R(1)-\frac{p}{2-p} \varepsilon$ and $R^{\prime}(0)=R(0)$ with $\varepsilon>0$ and small; thus $\Delta_{12}^{\prime}=\Delta_{12}-\varepsilon, \Delta_{20}^{\prime}=\Delta_{20}+\frac{2(1-p)}{2-p} \varepsilon$ and $\Delta_{12}^{\prime}+\Delta_{20}^{\prime}=\Delta_{12}+$ $\Delta_{20}-\frac{p}{2-p} \varepsilon$. Furthermore, we set $w_{2}^{\prime}=w_{2}+\left(1-q_{0}\right) \frac{2(1-p)}{2-p} \varepsilon$ and $w_{1}^{\prime}=w_{1}-\left(1-q_{0}\right) \frac{p}{2-p} \varepsilon$ and $q_{n}^{\prime}=q_{n}$ for $n=0,1,2$. First we verify that $G^{\prime}$ is feasible. Given that (16) holds in $G$, it follows that $\left(\mathrm{IC}_{20}\right)$ and $\left(\mathrm{IC}_{10}\right)$ are satisfied in $G^{\prime}$. On the other hand, $\left(\mathrm{IC}_{12}\right)$ reduces to $w_{1}-\left(1-q_{0}\right) \frac{p}{2-p} \varepsilon \geq\left(1-q_{2}\right)\left[\Delta_{12}-\varepsilon+w_{2}+\left(1-q_{0}\right) \frac{2(1-p)}{2-p} \varepsilon\right]$ and we know that $w_{1}=\left(1-q_{2}\right)\left(\Delta_{12}+w_{2}\right)$ given that $\left(\mathrm{IC}_{12}\right)$ binds in $G$. We need to prove that $\left(1-q_{2}\right)\left[\varepsilon-\left(1-q_{0}\right) \frac{2(1-p)}{2-p} \varepsilon\right] \geq\left(1-q_{0}\right) \frac{p}{2-p} \varepsilon$. From inserting the binding $\left(\mathrm{IC}_{12}\right)$ and $\left(\mathrm{IC}_{20}\right)$ into $\left(\mathrm{IC}_{10}\right)$, we obtain $\left(1-q_{2}\right)\left[\Delta_{12}+\left(1-q_{0}\right) \Delta_{20}\right] \geq\left(1-q_{0}\right)\left(\Delta_{12}+\Delta_{20}\right)$, which implies $1-q_{2} \geq 1-q_{0}$. Thus $\left(1-q_{2}\right)\left[\varepsilon-\left(1-q_{0}\right) \frac{2(1-p)}{2-p} \varepsilon\right] \geq\left(1-q_{0}\right)\left[\varepsilon-\left(1-q_{0}\right) \frac{2(1-p)}{2-p} \varepsilon\right]$ and it turns out that $\left(1-q_{0}\right)\left[\varepsilon-\left(1-q_{0}\right) \frac{2(1-p)}{2-p} \varepsilon\right] \geq\left(1-q_{0}\right) \frac{p}{2-p} \varepsilon$ holds. Regarding (BE), we find that the expected wage paid to the supervisor in $G^{\prime}$ is the same as in $G$ and the borrowers' expected payment is the same as in $G$; thus (BE) holds in $G^{\prime}$ as it holds in $G$. Finally, the 
borrowers' payoff is the same in $G^{\prime}$ as in $G$. In this way we have proved that whenever the lending contract is such that $\Delta_{12}>0$, there exists another feasible contract which is at least as good and has a smaller $\Delta_{12}$. Therefore we can find a solution to the relaxed problem by restricting our attention to contracts such that $\Delta_{12}=0$.

Given $\Delta_{12}=0$, we can argue like in the end of the proof of Step 3 in the proof of Lemma 2 to find that $\left(\mathrm{IC}_{10}\right)$ implies $q_{2}=0$ and $w_{1}=\left(1-q_{0}\right) \Delta_{20}$. This implies that the incentive constraints which have been neglected are satisfied. Therefore, in regime $\mathrm{D}$ there is no loss of generality in considering only the contracts such that $\Delta_{12}=0$.

4. $R(1) \geq R(0) \geq R(2)$ : regime $E$.

We show that within the set of grand contracts such that $R(1) \geq R(0) \geq R(2)$ the best contract $G^{E}$ is such that $R^{E}(0)=R^{E}(2)$; therefore, it belongs to regime $D$. Let $\Delta_{10} \equiv R(1)-R(0) \geq 0$ and $\Delta_{02} \equiv R(0)-R(2) \geq 0$. We study the relaxed program in which we consider only $\left(\mathrm{IC}_{10}\right),\left(\mathrm{IC}_{12}\right)$ and $\left(\mathrm{IC}_{02}\right)$ among the incentive constraints:

$$
\left\{\begin{array}{c}
\left(\mathrm{IC}_{10}\right) \quad w_{1} \geq\left(1-q_{0}\right)\left(\Delta_{10}+w_{0}\right) \\
\left(\mathrm{IC}_{12}\right) \quad w_{1} \geq\left(1-q_{2}\right)\left(\Delta_{10}+\Delta_{02}+w_{2}\right) \\
\left(\mathrm{IC}_{02}\right) \quad w_{0} \geq\left(1-q_{2}\right)\left(\Delta_{02}+w_{2}\right)
\end{array}\right.
$$

Suppose that $G$ is feasible in the relaxed problem and such that $\Delta_{02}>0$. Then we find $G^{\prime}$ which is strictly better than $G$ and satisfies $\Delta_{02}^{\prime}=0$. Precisely, let $w_{n}^{\prime}=w_{n}$ and $q_{n}^{\prime}=q_{n}$ for $n=0,1,2$ and $R^{\prime}(2)=R(2)+\left(1-p^{2}\right) \Delta_{02}, R^{\prime}(1)=R(1)-p^{2} \Delta_{02}, R^{\prime}(0)=R(0)-p^{2} \Delta_{02}$; then $\Delta_{02}^{\prime}=0<\Delta_{02}$ and $\Delta_{10}^{\prime}=\Delta_{10}$. As a consequence, the incentive constraints in (17) are weakly relaxed. Furthermore, the borrowers' expected payment and the expected wage bill are unchanged, thus (BE) is satisfied. Since $R^{\prime}(1)<R(1)$ and $R^{\prime}(0)<R(0)$, Lemma 6 implies that the borrowers' payoff is larger in $G^{\prime}$ than in $G$. Given $\Delta_{02}=0$ we can argue as in the proof of Step 1 in the proof of Lemma 2 and as in the analysis of regime $\mathrm{C}$ in this proof of Lemma 3 to find that $w_{2}=0, q_{1}=0, w_{0}=0$ and $q_{0}=q_{2}$, $w_{1}=\left(1-q_{0}\right) \Delta_{10}$; this implies that the incentive constraints which have been neglected are satisfied. This proves that $G^{E}$ satisfies $\Delta_{02}=0$.

\section{Proof of Lemma 4}

Suppose that a grand contract $G=\left\{r_{S}, r_{F}, w_{2}, w_{1}, w_{0}, q_{2}, q_{1}, q_{0}\right\}$ is feasible and such that $r_{S}<r_{F}$. Then we can find $G^{\prime}=\left\{r_{S}^{\prime}, r_{F}^{\prime}, w_{2}^{\prime}, w_{1}^{\prime}, w_{0}^{\prime}, q_{2}^{\prime}, q_{1}^{\prime}, q_{0}^{\prime}\right\}$ which is feasible and increases the borrowers' payoff with respect to $G$. Precisely, let $r_{S}^{\prime}=r_{F}^{\prime}=r^{e} \equiv p r_{S}+$ $(1-p) r_{F}$ and $w_{2}^{\prime}=w_{1}^{\prime}=w_{0}^{\prime}=0, q_{2}^{\prime}=q_{1}^{\prime}=q_{0}^{\prime}=0$. Then (a) $G^{\prime}$ satisfies all the incentive constraints since $\Delta=0$; (b) the financing cost with $G^{\prime}$ is equal to $2 \rho$, which is 
the minimum feasible cost and thus it cannot be larger than the cost under $G$; (c) the borrowers' expected payment [the left hand side of $(B E)$ ] with $G^{\prime}$ is the same as the one with $G$. Hence $G^{\prime}$ is feasible and the borrowers' payoff is $2\left[p Y_{S}-p r^{e}-(1-p) \psi\left(r^{e}\right)\right]$. The inequality $2\left[p Y_{S}-p r^{e}-(1-p) \psi\left(r^{e}\right)\right]>2\left[p Y_{S}-p r_{S}-(1-p) \psi\left(r_{F}\right)\right]$ is equivalent to $\psi\left(r_{F}\right)-\psi\left(r^{e}\right)>\frac{p}{1-p}\left(r^{e}-r_{S}\right)$ and we have $\frac{p}{1-p}\left(r^{e}-r_{S}\right)=r_{F}-r^{e}$. Therefore, the borrowers' payoff is higher in $G^{\prime}$ than in $G$ given that $\psi^{\prime}(r)>1$ for any $r>0$.

\section{Proof of Lemma 5}

When $\Delta=0$, contract $\alpha$ satisfies (7) and is the optimal supervisory contract as it generates a financing cost equal to $2 \rho$, which is the minimum feasible value. In the following we consider the case of $\Delta>0$.

Given $\Delta>0$, we can argue like in Steps 1 and 2 of the proof of Lemma 2 to prove that $q_{2}=0, w_{0}=0$ and $\left(\mathrm{IC}_{10}\right)$ and $\left(\mathrm{IC}_{21}\right)$ bind; thus $w_{1}=\left(1-q_{0}\right) \Delta$ and $w_{2}=\left(1-q_{1}\right)\left(2-q_{0}\right) \Delta$. Furthermore, $\left(\mathrm{IC}_{20}\right)$ reduces to $q_{1} \leq f\left(q_{0}\right)$, where $f\left(q_{0}\right) \equiv \frac{q_{0}}{2-q_{0}}$ is an increasing and convex function such that $f(0)=0$ and $f(1)=1$. The feasible set $F$ for $\left(q_{0}, q_{1}\right)$ is therefore $F=\left\{\left(q_{0}, q_{1}\right) \in \mathbb{R}_{+}^{2}: q_{0} \leq 1\right.$ and $\left.q_{1} \leq f\left(q_{0}\right)\right\}$. The total financing cost is

$$
Q\left(q_{0}, q_{1}\right)=2 \rho+p^{2}\left(1-q_{1}\right)\left(2-q_{0}\right) \Delta+2 p(1-p)\left[\left(1-q_{0}\right) \Delta+k q_{1}\right]+(1-p)^{2} k q_{0}
$$

and no point in the interior of $F$ minimizes $Q$ since the Hessian matrix of $Q$ is indefinite for any $\left(q_{0}, q_{1}\right)$ :

$$
\frac{\partial^{2} Q}{\partial q_{0}^{2}}=\frac{\partial^{2} Q}{\partial q_{1}^{2}}=0 \quad \text { and } \quad \frac{\partial^{2} Q}{\partial q_{0} \partial q_{1}}=p^{2} \Delta>0
$$

This violates the second order condition for a minimum, which requires the Hessian matrix to be positive semi-definite.

We can neglect any point $\left(\hat{q}_{0}, 0\right)$ on the south boundary of $F$ such that $\hat{q}_{0} \in(0,1)$ because $Q$ is linear in $q_{0}$ and therefore $\min \{Q(0,0), Q(1,0)\} \leq Q\left(\hat{q}_{0}, 0\right)$ for any $\hat{q}_{0} \in(0,1)$. Likewise, we can neglect any point $\left(1, \hat{q}_{1}\right)$ on the east boundary of $F$ such that $\hat{q}_{1} \in(0,1)$ because $Q$ is linear in $q_{1}$. As a consequence, only $\left(q_{0}, q_{1}\right)=(1,0)$ may be a minimum point for $Q$ in the subset of $F$ in which $\left(\mathrm{IC}_{20}\right)$ is slack, and that corresponds to contract $\beta$.

When also $\left(\mathrm{IC}_{20}\right)$ binds, we have $q_{1}=f\left(q_{0}\right)$ and $Q\left(q_{0}, q_{1}\right)$ is equal to

$$
\begin{aligned}
\bar{Q}\left(q_{0}\right) & \equiv Q\left[q_{0}, f\left(q_{0}\right)\right] \\
& =2 \rho+p^{2}\left[1-f\left(q_{0}\right)\right]\left(2-q_{0}\right) \Delta+2 p(1-p)\left[\left(1-q_{0}\right) \Delta+k f\left(q_{0}\right)\right]+(1-p)^{2} k q_{0} \\
& =2 \rho+2 p(1-p) k f\left(q_{0}\right)+(1-p)^{2} k q_{0}+2 p\left(1-q_{0}\right) \Delta
\end{aligned}
$$


Since $f$ is convex, also $\bar{Q}$ is so. Hence, $\bar{Q}$ is minimized at $q_{0}=0$ if $\bar{Q}^{\prime}(0) \geq 0$ (contract $\alpha$ ), at $q_{0}=1$ if $\bar{Q}^{\prime}(1) \leq 0$ (contract $\left.\gamma\right)$, at some $q_{0}^{*} \in(0,1)$ if $\bar{Q}^{\prime}(0)<0<\bar{Q}^{\prime}(1)$. However, $q_{0}^{*}$ is such that $\bar{Q}^{\prime}\left(q_{0}^{*}\right)=0$ which is equivalent to $\frac{\partial Q\left[q_{0}^{*}, f\left(q_{0}^{*}\right)\right]}{\partial q_{0}}+\frac{\partial Q\left[q_{0}^{*}, f\left(q_{0}^{*}\right)\right]}{\partial q_{1}} f^{\prime}\left(q_{0}^{*}\right)=0$. Since $f^{\prime}\left(q_{0}^{*}\right)>0$, it must be the case that $\frac{\partial Q\left[q_{0}^{*}, f\left(q_{0}^{*}\right)\right]}{\partial q_{0}}<0<\frac{\partial Q\left[q_{0}^{*}, f\left(q_{0}^{*}\right)\right]}{\partial q_{1}}$, or $\frac{\partial Q\left[q_{0}^{*}, f\left(q_{0}^{*}\right)\right]}{\partial q_{0}} \geq 0 \geq$ $\frac{\partial Q\left(q_{0}^{*}, f\left(q_{0}^{*}\right)\right]}{\partial q_{1}}$. In the first case we do not have an optimal supervisory contract because it is possible to reduce the cost by slightly increasing $q_{0}$ above $q_{0}^{*}$ and/or by slightly decreasing $q_{1}$ below $q_{1}^{*}=f\left(q_{0}^{*}\right)$. The proof is completed by showing that the second case cannot arise. Indeed, we find

$$
\begin{aligned}
& \frac{\partial Q}{\partial q_{0}}=-p^{2}\left(1-q_{1}\right) \Delta-2 p(1-p) \Delta+(1-p)^{2} k \\
& \frac{\partial Q}{\partial q_{1}}=-p^{2}\left(2-q_{0}\right) \Delta+2 p(1-p) k
\end{aligned}
$$

Then $\frac{\partial Q}{\partial q_{1}} \leq 0$ is equivalent to $k \leq \frac{p\left(2-q_{0}\right)}{2(1-p)} \Delta$ and this inequality implies $\frac{\partial Q}{\partial q_{0}} \leq-p^{2}(1-$ $\left.q_{1}\right) \Delta-2 p(1-p) \Delta+\frac{1}{2} p(1-p)\left(2-q_{0}\right) \Delta$. The right hand side of the last inequality is smaller than $-\Delta p(1-p)<0$ for any $\left(q_{0}, q_{1}\right) \in[0,1]^{2}$.

\section{Proof of Proposition 2}

The proof of Proposition 2(i)a-b appears in the text.

It is simple to verify that the neglected upward incentive constraints $\left(\mathrm{IC}_{12}\right),\left(\mathrm{IC}_{02}\right),\left(\mathrm{IC}_{01}\right)$ are satisfied by the two contracts described by Proposition 2(i).

Furthermore, we verify that $Y_{S}$ is large enough to make the borrowers' payoff positive in the optimal grand contract. For the state non-contingent contract described in (i)a, the borrowers' payoff is $2 p Y_{S}-2 \rho-2(1-p)[\psi(\rho)-\rho]$ and A1(i) implies that this payoff is positive. For the state-contingent contract described in Proposition 2(i)b, the borrowers' payoff is $2\left(p Y_{S}-p \Delta_{I}^{\max }\right)=2 p Y_{S}-2 \rho-\left(1-p^{2}\right) k$ and is positive given A1(i). 